Research Article

\title{
Comparison of the Flexural Performance and Behaviour of Fly-Ash-Based Geopolymer Concrete Beams Reinforced with CFRP and GFRP Bars
}

\author{
Hemn Qader Ahmed 1 , Dilshad Kakasor Jaf, and Sinan Abdulkhaleq Yaseen \\ Department of Civil Engineering, Salahaddin University-Erbil, Erbil, Iraq \\ Correspondence should be addressed to Hemn Qader Ahmed; hemn.ahmed@su.edu.krd
}

Received 4 April 2019; Revised 25 November 2019; Accepted 26 December 2019; Published 11 January 2020

Academic Editor: Charles C. Sorrell

Copyright (c) 2020 Hemn Qader Ahmed et al. This is an open access article distributed under the Creative Commons Attribution License, which permits unrestricted use, distribution, and reproduction in any medium, provided the original work is properly cited.

\begin{abstract}
A construction system with high sustainability, high durability, and appropriate strength can be supplied by geopolymer concrete (GPC) reinforced with glass fibre-reinforced polymer (GFRP) bars and carbon fibre-reinforced polymer (CFRP) bars. Few studies deal with a combination of GPC and FRP bars, especially CFRP bars. The present investigation presents the flexural capacity and behaviour of fly-ash-based GPC beam reinforced with two different types of FRP bars: six reinforced geopolymer concrete (RGPC) beams consisting of three specimens reinforced with GFRP bars and the rest with CFRP bars. The beams were tested under fourpoint bending with a clear span of $2000 \mathrm{~mm}$. The test parameters included the longitudinal-reinforcement ratio and the longitudinal-reinforcement type, including GFRP and CFRP. Ultimate load, first crack load, load-deflection behaviour, load-strain curve, crack width, and the modes of failure were studied. The experimental results were compared with the equations recommended by ACI 440.1R-15 and CSA S806-12 for flexural strength and midspan deflection of the beams. The results show that the reinforcement ratio had a significant effect on the ultimate load capacity and failure mode. The ultimate load capacity of CFRPRGPC beams was higher than that of GFRP-RGPC, more crack formations were observed in the CFRP-RGPC beams than in the GFRP-RGPC beams, and the crack width in the GFRP-RGPC beams was more extensive than that in the CFRP-RGPC beams. Beams with lower reinforcement ratios experienced a fewer number of crack and a higher value of crack width, while numerous cracks and less value of crack width were observed in beams with higher reinforcement ratio. Beams with the lower reinforcement ratios were more affected by the type of FRP bars, and the deflection in GFRP-RGPC beams was higher than that in CFRP-RGPC beams for the same corresponding load level. ACI 440.1R-15 and CSA S806-12 underestimated the flexural strength and midspan deflection of RGPC beams; however, CSA S806-12 predicted more accurately.
\end{abstract}

\section{Introduction}

The ordinary portland cement concrete (OPCC) is one of the most commonly used and oldest building materials in the world. The order for this material is expected to increase in the future due to the increasing demand for infrastructure in many developing countries-the rising number of old and deteriorating concrete structures that desperately need repair and rehabilitation. The production of cement, however, contributes billions of tons of waste materials and about 7\% of the world's greenhouse gas yearly [1]. The global environmental issues found during the manufacture of cement at certain stages are undesirable. Producing a ton of cement cause to launch the quantity of one ton of carbon dioxide to the atmosphere; this is due to the calcination of limestone and burning of fossil gas during the manufacturing of cement $[2,3]$. The utilisation of green concrete in construction is increasingly adopted by the construction industry owing to the drawbacks of normal concrete and the various inherent benefits of green concrete. Green concrete comes in multiple forms such as high-volume fly ash concrete, ultrahigh performance concrete, geopolymer concrete, and lightweight concrete [4]. In 1988, Davidovits introduced the term "geopolymer" and discovered a new binder, which may 
be obtained by activating the (silicon and aluminium) in the source material, fly ash and rice husk ash with an alkaline activator [5]. Geopolymer concrete is a new type of concrete without the use of cement, and engineering scientists benefit from chemistry to produce GPC [6].

Recently, it has been investigated environmentalfriendly railway sleepers [7], modular retaining walls [8], sustainable buildings [9], and sustainable CFRP-reinforced recycled concrete for cleaner eco-friendly construction with new and alternative materials [10]. The researchers are now providing specific attention to the sustainable construction that motivates to investigate the concrete beams manufactured with GPC and FRP bars.

The alkalinity of the concrete protects the steel reinforcement from the corrosion. Some structures have been found to counter the violent climate (marine system bridges and garages) and exposure to deicing salts and combos of moisture, temperature, and chlorides decrease the alkalinity of the concrete then result in the corrosion of steel reinforcement. Because fibre-reinforced polymer (FRP) bars are noncorrosive and nonmagnetic, the issue of steel corrosion and the electromagnetic interface can be eliminated. Additionally, FRP bars have excessive tensile stress, making them proper to use as a structural reinforcement [11].

Researchers have done several investigations on flexural behaviour of steel reinforced-reinforced geopolymer concrete (SR-RGPC) beams. Load-deflection characteristics gained from steel reinforced-reinforced ordinary portland concrete (SR-ROPC) and SR-RGPC beams are almost similar. The ultimate load-carrying capacity of SR-RGPC beams was a little bit higher [12-16]. The first cracking load of SR-RGPC beams is better than that of SR-ROPC beams, which shows better load-carrying capacity [17]. Failure of SR-RGPC beams is more ductile in a manner than SR-ROPC beams, accompanied by crushing of concrete in the compression zone, and SR-RGPC beams exhibit a higher number of narrow cracks compared to the SR-ROPC beams [18]. Maranan et al. have investigated the flexural strength of glass fibre-reinforced polymer-reinforced geopolymer concrete (GFRP-RGPC) beams. The authors argued that the diameter of the bar had no significant effect on the beam's flexural performance, and the serviceability behaviour of a beam enhanced when the reinforcement ratio increases [19]. The GFRP-RGPC beams have structural properties that are suitable for civil infrastructure applications [20].

The adoption of FRP bars in place of steel bars as the primary internal reinforcement for concrete structures is now commonly practised to enhance the durability and prolong the serviceability of the structures, while the use of geopolymer concrete instead of cement-based concrete is particularly suitable for the fabrication of environmentfriendly concrete structures. With the advantageous characteristics of the FRP bars and the GPC, including their successful applications in the construction of various civil infrastructures, combining FRP and GPC would offer a promising technology in building new structures with high durability and high sustainability and with adequate strength and structural integrity. Most of the researchers focused on replacing OPC by GPC in steel-reinforced concrete structures. There is a limited study that combined the GPC with GFRP bars, by taking limited parameters [19], and the only study that uses CFRP bars in GPC beams has been undertaken by Ahmed et al. [21], in which the investigated parameters were the reinforcement ratio and concrete type. A logical step, therefore, is to investigate the flexural behaviour of GPC beams reinforced with two common types of FRP bars (GFRP and CFRP) by achieving a precise comparison condition. Reinforcement ratio and FRP types were taken as investigated parameters. The crack pattern, modes of failure, load-deflection curves, loadstrain curves, load-crack width, and strain in concrete and bars are presented. Furthermore, the experimental results compared with the predicted flexural capacities using the proposed equations of ACI 440.1R-15 [11] and CSA S80612 [22].

\section{Experimental Program}

2.1. Test Specimens and Program. The specimens were designed according to ACI 440.1R-15 [11]. The experimental program consists of six RGPC beams with the same target compressive strength $(50 \mathrm{MPa})$ and divided into two groups: three specimens reinforced with GFRP bars (G1) and the rest with CFRP bars (G2) [21], and the properties of fabric texture coated FRP bars are presented in Table 1. All the test specimens have a height of $300 \mathrm{~mm}$, while the width of specimens in G1 and G2 [21] was 160 and $110 \mathrm{~mm}$, respectively. The reason for choosing a different width in the two groups is to achieve the same reinforcement ratio $\left(\rho_{\mathrm{f}}<\rho_{\mathrm{fb}}, \quad \rho_{\mathrm{fb}}<\rho_{\mathrm{f}}<1.4 \rho_{\mathrm{fb}}, \quad\right.$ and $\left.\rho_{\mathrm{f}}>1.4 \rho_{\mathrm{fb}}\right)$ and also to maintain the three modes of failure (tension failure, balanced failure, and compression failure). The clear cover was kept at $20 \mathrm{~mm}$ for all beams. The length of the beams was varied $(2200$ or $2500 \mathrm{~mm}$ ) due to the requirement of development length by ACI 440.1R-15 [11]. Deformed steel bars of $6 \mathrm{~mm}$ diameter were used for top longitudinal reinforcement and stirrups. The stirrups were placed in a centre-to-centre spacing of $100 \mathrm{~mm}$ to prevent the shear failure of the beams. The beams were simply supported over a clear span of $2000 \mathrm{~mm}$.

The beam series were coded in the form (X\#1GPC\#2), which stands for the following: first letter (X) refers to FRP reinforcement type, which may take the value (C, or $\mathrm{G}), \mathrm{C}$ for carbon, and $\mathrm{G}$ for glass. The second value $(\# 1)$ is the beam number in groups. GPC refers to concrete type geopolymer concrete, and finally the fourth value (\#2) is the concrete compressive strength. The details of the specimens are shown in Figure 1, and Table 2 shows the test program.

2.2. Investigated Parameters. The first parameter investigated in this study was the reinforcement ratio $\left(\rho_{\mathrm{f}}\right)$ with respect to the balanced reinforcement ratio $\left(\rho_{\mathrm{fb}}\right)$. Three different reinforcement ratio conditions $\left(\rho_{\mathrm{f}}<\rho_{\mathrm{fb}}, \quad \rho_{\mathrm{fb}}<\rho_{\mathrm{f}}<1.4 \rho_{\mathrm{fb}}\right.$, and $\left.\rho_{\mathrm{f}}>1.4 \rho_{\mathrm{fb}}\right)$ were taken for each group (G1: GFRP-RGPC beams; G2: CFRP-RGPC beams [21]). The second investigated parameter was the types of FRP bars. Two common 
TABLE 1: Properties of FRP bars.

\begin{tabular}{lccccc}
\hline Type & Bar diameter $(\mathrm{mm})$ & Area $A_{\mathrm{f}}\left(\mathrm{mm}^{2}\right)$ & Ultimate tensile stress $f_{\mathrm{fu}}(\mathrm{MPa})$ & Elastic modulus $E_{\mathrm{f}}(\mathrm{GPa})$ & Ultimate strain $(\%)$ \\
\hline GFRP bars & 6 & 28 & 1280 & 46 & 2.7 \\
CFRP bars & 6 & 28 & 2000 & 148 & 1.4 \\
\hline
\end{tabular}
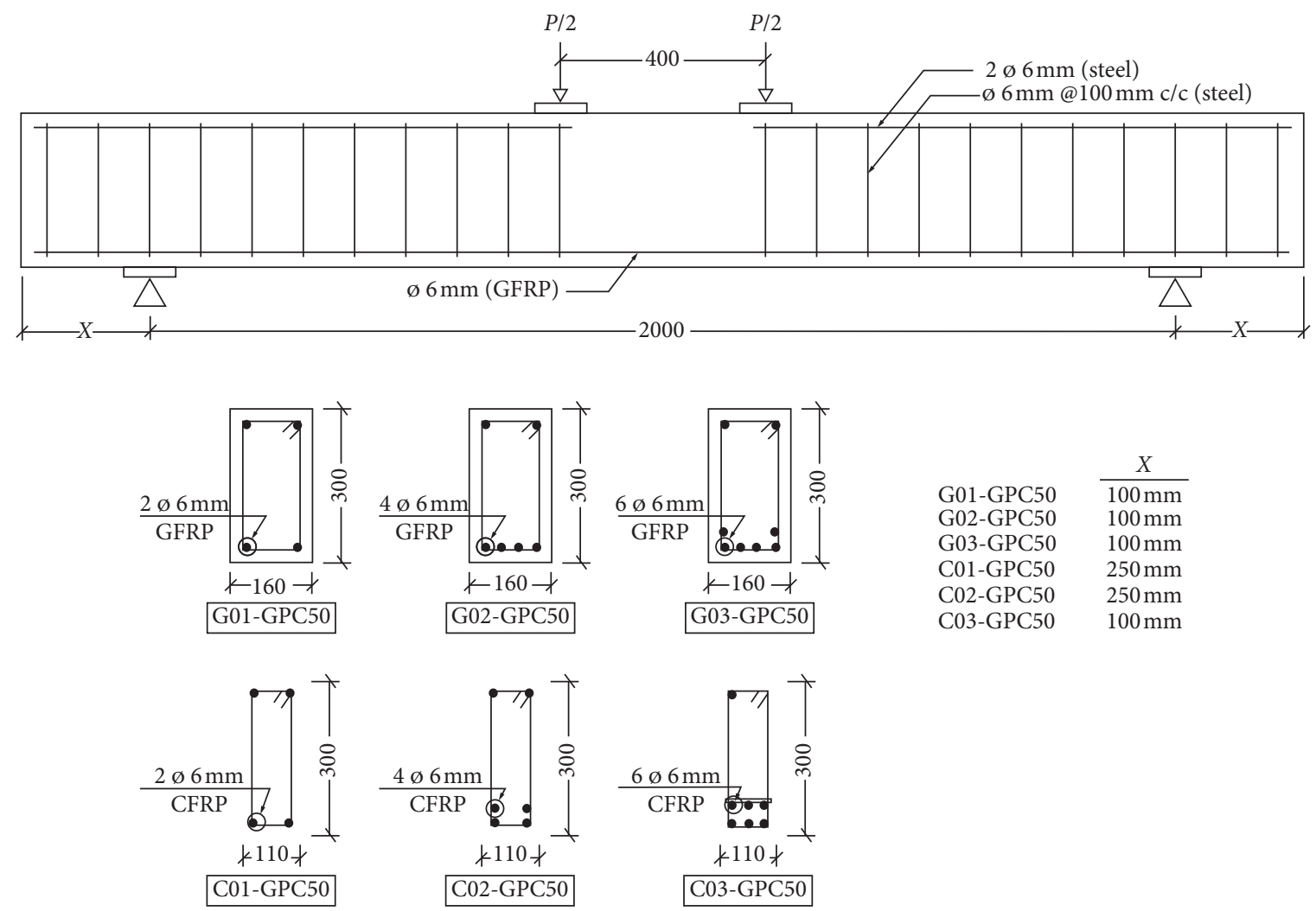

Figure 1: Dimensions and reinforcement details of the test specimens (dimensions are in $\mathrm{mm}$ ).

TABLE 2: Test program.

\begin{tabular}{|c|c|c|c|c|c|c|c|}
\hline \multirow[b]{2}{*}{ Group } & \multirow[b]{2}{*}{$\begin{array}{l}\text { Specimen } \\
\text { ID }\end{array}$} & \multirow[b]{2}{*}{$\begin{array}{l}\text { FRP } \\
\text { type }\end{array}$} & \multicolumn{2}{|c|}{ Beam section } & \multirow[b]{2}{*}{$\begin{array}{c}\text { Compressive strength } f_{\mathrm{c}}^{\prime} \\
(\mathrm{MPa})\end{array}$} & \multirow[b]{2}{*}{$\begin{array}{l}\text { Reinforcement ratio } \\
\text { condition }\end{array}$} & \multirow[b]{2}{*}{$\begin{array}{l}\text { Predicted mode } \\
\text { failure }\end{array}$} \\
\hline & & & $\begin{array}{c}b \\
(\mathrm{~mm})\end{array}$ & $\begin{array}{c}h \\
(\mathrm{~mm})\end{array}$ & & & \\
\hline G1 & $\begin{array}{l}\text { G01-GPC50 } \\
\text { G02-GPC50 } \\
\text { G03-GPC50 }\end{array}$ & GFRP & 160 & 300 & 50 & $\begin{array}{c}\rho_{\mathrm{f}}<\rho_{\mathrm{fb}} \\
\rho_{\mathrm{fb}}<\rho_{\mathrm{f}}<1.4 \rho_{\mathrm{fb}} \\
\rho_{\mathrm{f}}>1.4 \rho_{\mathrm{fb}}\end{array}$ & $\begin{array}{c}\text { Tension failure } \\
\text { Balanced failure } \\
\text { Compression failure }\end{array}$ \\
\hline G2 & $\begin{array}{l}\text { C01-GPC50 } \\
\text { C02-GPC50 } \\
\text { C03-GPC50 }\end{array}$ & CFRP & 110 & 300 & 50 & $\begin{array}{c}\rho_{\mathrm{f}}<\rho_{\mathrm{fb}} \\
\rho_{\mathrm{fb}}<\rho_{\mathrm{f}}<1.4 \rho_{\mathrm{fb}} \\
\rho_{\mathrm{f}}>1.4 \rho_{\mathrm{fb}}\end{array}$ & $\begin{array}{c}\text { Tension failure } \\
\text { Balanced failure } \\
\text { Compression failure }\end{array}$ \\
\hline
\end{tabular}

types of FRP bars were selected (GFRP and CFRP bars) as longitudinal flexural reinforcement; beams in groups G1 and G2 were reinforced with GFRP and CFRP bars [21], respectively.

2.3. Materials. Fabric texture coated GFRP and CFRP of $6 \mathrm{~mm}$ were used as main flexural reinforcement, while, $6 \mathrm{~mm}$ deformed steel bars were used for the rest reinforcement. Sodium silicate solution $\left(\mathrm{Na}_{2} \mathrm{SiO}_{3}\right)$, which is available in liquid gel form with a chemical composition $\left(\mathrm{Na}_{2} \mathrm{O}-13.4 \%\right.$, $\mathrm{SiO}_{2}-32.5 \%$, and water-54.1\%), and sodium hydroxide $(\mathrm{NaOH})$ pellets with $98 \%$ purity, which are available in flakes and pellet shapes, were used for preparing the alkaline liquid.

For preparing the GPC, the constituent materials were the low calcium fly-ash type F, coarse aggregates with a maximum size of $9.52 \mathrm{~mm}$, and fine aggregates. The grading of aggregates satisfied with the limits provided by ASTM C33 [23]. Sulphonated naphthalene formaldehyde superplasticiser was used to enhance the workability. 
2.4. Control Specimens. The control specimens of each beam were tested at the same age of the tested beam. Three cylinders were tested according to ASTM C39 [24] for concrete compressive strengths. For splitting tensile strengths, three cylinders were tested according to ASTM C 496 [25]. Three prisms were tested for flexural strength of concrete according to ASTM C78 [26]. Furthermore, the modulus of elasticity of GPC and Poisson's ratio were determined by testing three cylinders according to ASTM C469 [27]. The density for each mix was calculated based on cylinders and prisms. Table 3 shows the results of the control specimens.

2.5. Geopolymer Concrete Preparation. The alkaline liquid was prepared a day before casting. First, the sodium hydroxide was dissolved in water according to the required molarity (M). For M12, as an example, the amount of sodium hydroxide required to be dissolved in water to get one litre of sodium hydroxide solution was $(12 \mathrm{x}$ molecular weight of sodium hydroxide $(4)=480$ grams), and also the experimentally determined weight of one litre of sodium hydroxide of $12 \mathrm{M}$ was 1330 grams. Second, sodium silicate and sodium hydroxide solutions were mixed in a ratio of 2.5 : 1 , which is the preferred ratio according to a previous research work [2].

Water-binder ratio was calculated as follows: the amount of water in sodium silicate solution, sodium hydroxide, and extra water divided by the solid parts in sodium silicate solution, sodium hydroxide solution, and fly ash.

At casting day, first, the aggregates were placed into an electric mixer, and half of the extra water added and mixed for $5 \mathrm{~min}$. Fly ash was added and mixed for an additional $5 \mathrm{~min}$, after that the alkaline liquid was added to the mixture. The remaining extra water and superplasticiser of $2 \%$ of the weight of fly ash were added. The fresh GPC was cast into steel moulds that were coated internally with special tape to avoid sticking of GPC with the mould. The time between casting and placing the GPC specimens into an oven is called "rest period." The rest period was $60 \mathrm{~min}$ before placing the casted GPC into an oven and cured for $24 \mathrm{hr}$ at a temperature of $70^{\circ} \mathrm{C}$. The oven-dry method was used for curing the GPC specimens.

2.6. Mix Proportion. In this study, ten trial mixes were performed for achieving the required compressive strength for GPC beams. The selected parameters for the trial mixes were based on methods proposed by Ferdous et al. [28] and Patankar et al. [29]. Molarity of sodium hydroxide, alkalinefly ash ratio, and the water-binder ratio were taken as variables. Table 4 shows the details of trial mix proportions. Each trial consists of nine $100 \times 200 \mathrm{~mm}$ cylinders, which were tested according to ASTM C33 [23] after 3, 7, and 28 days.

As a result, increasing molarity of sodium hydroxide caused to increase compressive strength up to $12 \mathrm{M}$, but when increased to $16 \mathrm{M}$, compressive strength decreased. When alkaline-fly ash ratio was increased, it resulted in an increase in the compressive strength, and the optimum water-binder ratio was 0.25 . Figure 2 shows the effect of trial mix parameters on compressive strength.

2.7. Casting Beam Specimens. From the trial mix results, T3 was selected as a proportion that has recorded the highest compressive strength. Before casting procedure, the reinforcement was prepared, including the attaching strain gauges. The casting moulds for RGPC beams consist of steel mould, while three cylinders $150 \times 300 \mathrm{~mm}$ and three prisms $75 \times 75 \times 400 \mathrm{~mm}$ were used for casting the control specimens. The mould, cylinders, and prisms were internally coated with a special tape for the same reason mentioned earlier and then placed on an external vibrator.

In this study, the oven-dry method was used for curing the GPC. According to Hardjito et al. [30], the suitable curing temperature was in the range of $30^{\circ} \mathrm{C}$ to $90^{\circ} \mathrm{C}$, and they found that curing of geopolymer concrete at higher temperatures up to $60^{\circ} \mathrm{C}$ yielded a higher compressive strength than at a lower temperature. Kirschner and Harmuth [31] obtained the highest strength using alkali-activated metakaolin cured at $75^{\circ} \mathrm{C}$ during $4 \mathrm{hrs}$. However, the selection of curing temperature for the current study was based on the information mentioned. The longer curing time, in the range of 4 to 96 hours, produces higher compressive strength of fly ash-based geopolymer concrete, according to Hardjito et al. [30] However, the increase in strength beyond 24 hours is not significant. For this reason, 24 hours curing time was selected.

After casting, the specimens were left for $60 \mathrm{~min}$ as a rest period and then placed into the oven and cured for $24 \mathrm{hr}$ at a temperature of $70^{\circ} \mathrm{C}$. Next day, the specimens were demoulded and placed in a laboratory environment until the test day. Figure 3 shows the casted beam specimen inside the oven.

2.8. Test Method and Instrumentations. In this study, a fourpoint static bending test method was employed, as shown in Figure 4. The beams were loaded at midspan with two concentrated loads spaced at $400 \mathrm{~mm}$. The load was applied using a hydraulic Jack of capacity $2500 \mathrm{kN}$ at a rate of approximately of $2 \mathrm{kN} / \mathrm{min}$. The midspan deflection was measured using a dial gauge and cam recorder. Furthermore, data logger was used for recording strains in electrical strain gauges that were attached to the top surface of the beams, and the strains in FRP bars and also a crack measurement sensor were used for recording the crack width.

\section{Results and Discussion}

The test results for the first cracking load, ultimate load, deflection, and failure modes are presented in Table 5.

3.1. Crack Pattern and Failure Mode. The crack patterns at the failure of GFRP-RGPC and CFRP-RGPC beams are shown in Figure 5. The crack patterns and modes of failure were dissimilar due to the value of reinforcement ratio and the type of used FRP bars. All the tested beams were initially 
TABLE 3: Results of the control specimens.

\begin{tabular}{|c|c|c|c|c|c|c|c|}
\hline Group & $\begin{array}{l}\text { Specimen } \\
\text { ID }\end{array}$ & $\begin{array}{c}\text { Compressive strength } \\
f_{\mathrm{c}}^{\prime}(\mathrm{Mpa})\end{array}$ & $\begin{array}{l}\text { Tensile strength } f_{\mathrm{ct}} \\
(\mathrm{Mpa})\end{array}$ & $\begin{array}{l}\text { Flexural strength } f_{\mathrm{r}} \\
(\mathrm{Mpa})\end{array}$ & $\begin{array}{c}\text { Elastic modulus } E_{\mathrm{c}} \\
(\mathrm{Mpa})\end{array}$ & $\begin{array}{l}\text { Poisson's } \\
\text { ratio }(\mu)\end{array}$ & $\begin{array}{l}\text { Density } \\
\left(\mathrm{kg} / \mathrm{m}^{3}\right)\end{array}$ \\
\hline \multirow{3}{*}{ G1 } & $\begin{array}{c}\text { G01- } \\
\text { GPC50 }\end{array}$ & 46.28 & 3.599 & 4.81 & 29066 & 0.13 & 2427 \\
\hline & $\begin{array}{c}\text { G02- } \\
\text { GPC50 }\end{array}$ & 45.12 & 3.167 & 4.92 & 26691 & 0.16 & 2387 \\
\hline & $\begin{array}{c}\text { G03- } \\
\text { GPC50 }\end{array}$ & 45.44 & 3.272 & 4.46 & 25771 & 0.12 & 2370 \\
\hline \multirow{3}{*}{ G2 } & $\begin{array}{c}\text { C01- } \\
\text { GPC50 }\end{array}$ & 44.66 & 3.552 & 4.93 & 29582 & 0.16 & 2386 \\
\hline & $\begin{array}{c}\mathrm{C} 02- \\
\text { GPC50 }\end{array}$ & 47.49 & 4.456 & 5.33 & 32272 & 0.14 & 2393 \\
\hline & $\begin{array}{c}\text { C03- } \\
\text { GPC50 }\end{array}$ & 45.41 & 4.084 & 5.53 & 29582 & 0.15 & 2431 \\
\hline
\end{tabular}

TABLE 4: Trial mix proportion details and results.

\begin{tabular}{|c|c|c|c|c|c|c|c|c|c|c|c|c|}
\hline \multirow[b]{2}{*}{ Trial } & \multirow{2}{*}{$\begin{array}{c}\mathrm{G} \\
\left(\mathrm{kg} / \mathrm{m}^{3}\right)\end{array}$} & \multirow{2}{*}{$\begin{array}{c}\mathrm{S} \\
\left(\mathrm{kg} / \mathrm{m}^{3}\right)\end{array}$} & \multirow{2}{*}{$\begin{array}{c}\text { FA } \\
\left(\mathrm{kg} / \mathrm{m}^{3}\right)\end{array}$} & \multirow[b]{2}{*}{$\mathrm{M}$} & \multirow[b]{2}{*}{$\mathrm{S} / \mathrm{S}$} & \multirow[b]{2}{*}{$\mathrm{A} / \mathrm{F}$} & \multirow{2}{*}{$\begin{array}{c}\text { EW } \\
\left(\mathrm{kg} / \mathrm{m}^{3}\right)\end{array}$} & \multirow{2}{*}{$\begin{array}{c}\mathrm{SP} \% \\
\left(\mathrm{~kg} / \mathrm{m}^{3}\right)\end{array}$} & \multirow[b]{2}{*}{$\begin{array}{l}\mathrm{W} / \mathrm{B} \\
\text { ratio }\end{array}$} & \multicolumn{3}{|c|}{ Compressive strength, $f_{\mathrm{c}}^{\prime}$} \\
\hline & & & & & & & & & & $\begin{array}{l}3 \text { days } \\
(\mathrm{MPa})\end{array}$ & $\begin{array}{l}7 \text { days } \\
(\mathrm{MPa})\end{array}$ & $\begin{array}{c}28 \text { days } \\
\text { (MPa) }\end{array}$ \\
\hline $\mathrm{T} 1$ & 1230 & 660 & 400 & 12 & 2.5 & 0.45 & 0 & 3 & 0.2145 & 41.6 & 42.7 & 45.5 \\
\hline $\mathrm{T} 2$ & 1230 & 660 & 400 & 12 & 2.5 & 0.45 & 32 & 2 & 0.3017 & 35.8 & 36.5 & 39.5 \\
\hline T3 & 1230 & 660 & 400 & 12 & 2.5 & 0.45 & 14 & 2 & 0.2511 & 44.2 & 45.5 & 47.5 \\
\hline $\mathrm{T} 4$ & 1230 & 660 & 400 & 12 & 2.5 & 0.45 & 48 & 2 & 0.3502 & 22.2 & 22.3 & 26.8 \\
\hline T5 & 1230 & 660 & 400 & 16 & 2.5 & 0.45 & 36 & 2 & 0.3009 & 34.7 & 36.2 & 39.4 \\
\hline T6 & 1230 & 660 & 400 & 8 & 2.5 & 0.45 & 27 & 2 & 0.3019 & 19.4 & 19.5 & 24.6 \\
\hline T7 & 1230 & 660 & 400 & 8 & 2.5 & 0.45 & 43 & 2 & 0.3504 & 14.1 & 14.5 & 19.5 \\
\hline T8 & 1230 & 660 & 400 & 8 & 2.5 & 0.4 & 50 & 2 & 0.3512 & 9.3 & 9.5 & 12.9 \\
\hline T9 & 1230 & 660 & 400 & 8 & 2.5 & 0.35 & 57 & 2 & 0.3521 & 7.9 & 8.5 & 10.4 \\
\hline $\mathrm{T} 10$ & 1230 & 660 & 400 & 12 & 2.5 & 0.45 & 38 & 2 & 0.3195 & 28.2 & 29.7 & 34.5 \\
\hline
\end{tabular}

Note. G: coarse aggregate; S: sand; FA: fly ash; M: molarity of sodium hydroxide; S/S: sodium silicate-sodium hydroxide ratio; A/F: alkaline-fly ash ratio; EW: extra water; SP: superplasticiser; W/B: water-binder ratio.

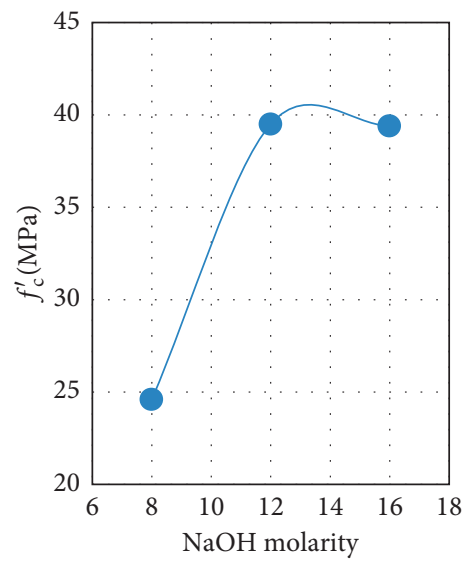

(a)

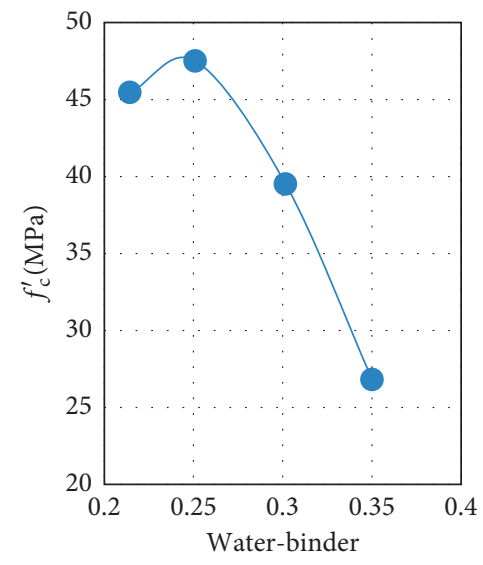

(b)

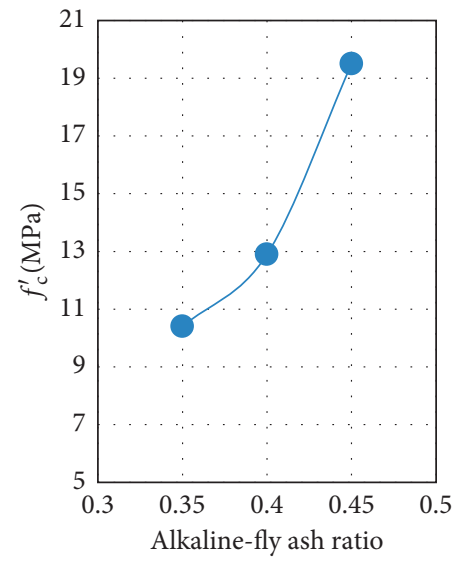

(c)

FIGURE 2: Effect of trial mix parameters on compressive strength. (a) Molarity effect. (b) Water-binder effect. (c) Alkaline-fly ash effect.

uncracked before loading. The initial cracking of the GFRPRGPC and CFRP-RGPC beams occurred at the constant moment region precisely under the load. The first cracking load in GFRP-RGPC beams (avg. $20.6 \mathrm{kN}$ ) was a bit higher than that in CFRP-RGPC beams (avg. $16.8 \mathrm{kN}$ ); even both have the same compressive strength, and this due to the beam width change for achieving the same reinforcement ratio condition. After the first cracking, new cracks formed, and the widths of the existing cracks continued to enlarge with the load in both GFRP-RGPC and CFRP-RGPC. At maximum load, more cracks formed in the CFRP-RGPC beams $(6,11$, and 13$)$ than in the GFRP-RGPC beams $(5,6$, 


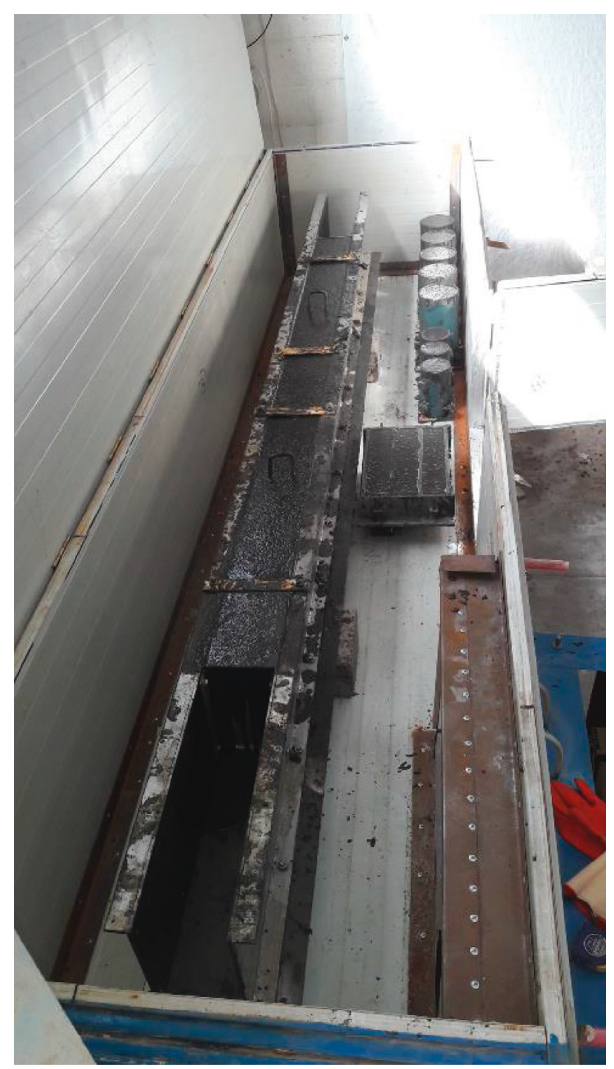

Figure 3: Casted beam specimen inside the oven.

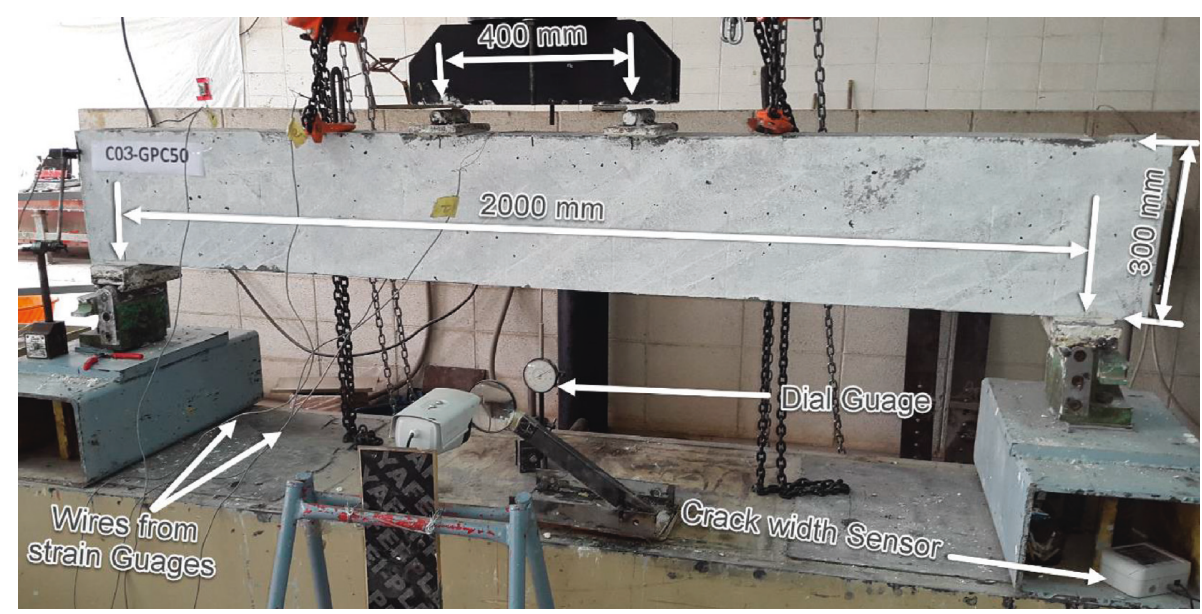

Figure 4: Test setup.

and 8), and this is due to the types of FRP bars. As average, the crack width in the GFRP-RGPC beams $(2.81,2.54$, and 2.61) was wider than that in the CFRP-RGPC beams ( 3.59 , 1.64 , and 1.23), and the reason beyond this is the higher modulus of elasticity of the CFRP bars than the GFRP bars.

Beams G01-GPC50 and C01-GPC50 failed due to the rupture of FRP bars (tension failure) exactly at midspan as shown in figures 5(a) and 5(b), and the beams were reinforced with $\rho_{\mathrm{f}}<\rho_{\mathrm{fb}}$. The beams experienced a fewer number of cracks and a higher value of crack width compared with rest values of reinforcement ratio. The cracks were mainly vertical flexural cracks that were perpendicular to the longitudinal axis of the beam.

Failure modes in beams G02-GPC50 and C02-GPC50 were a bit different as shown in figures $5(\mathrm{c})$ and $5(\mathrm{~d})$, because of the critical reinforcement ratio condition $\rho_{\mathrm{fb}}<\rho_{\mathrm{f}}<1.4 \rho_{\mathrm{fb}}$, due to the assumed values for strain and target compressive strength. Beam G02-GPC50 failed due to the rapture of FRP bar and followed by the crushing of concrete under the load (balanced failure) failure, while beam C02-GPC50 failed by crushing of concrete at compression zone between the two-point loads (compression 
TABLE 5: Results of the tested beams.

\begin{tabular}{|c|c|c|c|c|c|c|}
\hline Group & $\begin{array}{l}\text { Specimen } \\
\text { ID }\end{array}$ & Reinforcement ratio $\rho_{\mathrm{f}}$ & First crack load $P_{\mathrm{cr}}(\mathrm{kN})$ & Ultimate load $P_{\mathrm{u}}(\mathrm{kN})$ & Deflection $\Delta(\mathrm{mm})$ & Failure mode \\
\hline \multirow{3}{*}{ G1 } & G01-GPC50 & $0.67 \rho_{\mathrm{fb}}$ & 18.30 & 57.700 & 28.42 & \multirow{3}{*}{$\begin{array}{c}\text { Tension failure } \\
\text { Balanced failure } \\
\text { Compression } \\
\text { failure }\end{array}$} \\
\hline & G02-GPC50 & $1.34 \rho_{\mathrm{fb}}$ & 20.8 & 100.000 & 28.98 & \\
\hline & G03-GPC50 & $2.07 \rho_{\mathrm{fb}}$ & 22.60 & 145.800 & 35.17 & \\
\hline \multirow{3}{*}{ G2 } & C01-GPC50 & $0.66 \rho_{\mathrm{fb}}$ & 14.8 & 112.5 & 27.5 & \multirow{3}{*}{$\begin{array}{c}\text { Tension failure } \\
\text { Compression } \\
\text { failure } \\
\text { Compression } \\
\text { failure }\end{array}$} \\
\hline & C02-GPC50 & $1.38 \rho_{\mathrm{fb}}$ & 15.7 & 154.1 & 22.5 & \\
\hline & C03-GPC50 & $2.07 \rho_{\mathrm{fb}}$ & 19.9 & 169.8 & 19.2 & \\
\hline
\end{tabular}

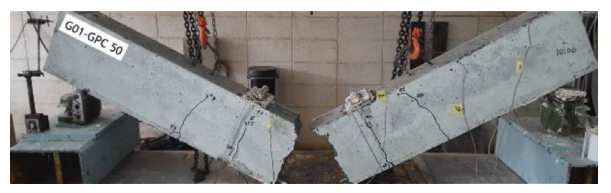

(a)

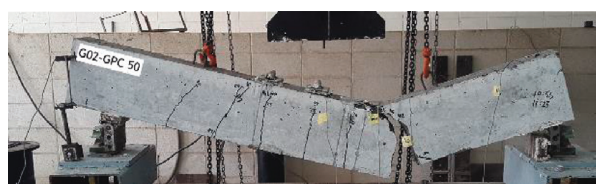

(c)

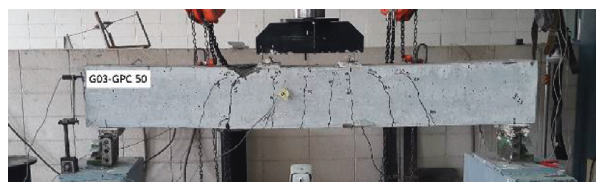

(e)

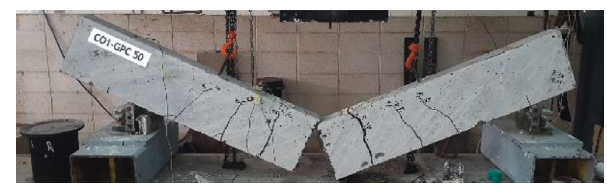

(b)

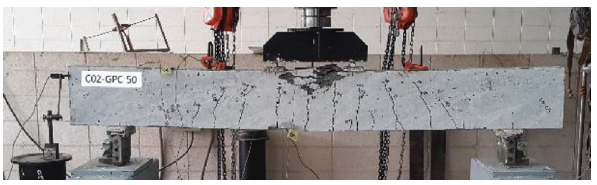

(d)

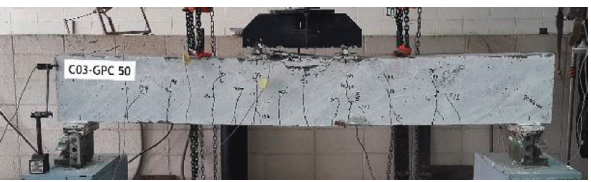

(f)

Figure 5: Crack pattern and failure mode. (a) G01-GPC50. (b) C01-GPC50. (c) G02-GPC50. (d) C02-GPC50. (e) G03-GPC50. (f) C03GPC50.

failure). Beam G02-GPC50 recorder higher crack width and lower number of crack over the beam C02-GPC50. As a result, for this particular reinforcement condition, the limitation provided by ACI 440.1R-15 [11] gives different modes of failure for GFRP-RGPC and CFRP-RGPC beams even satisfied with GFRP-RGPC beams.

The vertical flexural cracks in the shear span become more inclined during the last stage of the loading in beams G03-GPC50 and C03-GPC50 with reinforcement ratio $\rho_{\mathrm{f}}>1.4 \rho_{\mathrm{fb}}$, due to the shear stresses. Both beams failed due to the crushing of concrete at the top surface of the beams (compression failure) in different location, as shown in Figures 5(e) and 5(f). Crushing locations were under the point load and between point loads in G03GPC50 and C03-GPC50 beams, respectively, due to the variance in beam width, which was the cause for the increase in the distance between the neutral axis and top of the concrete. The beams in this reinforcement condition recorded numerous cracks and less value of crack width besides other conditions, while the crack width seemed to be the smallest for beam C03-GPC50. The load and crack width relationship for all the tested beams are shown in Figure 6.
3.2. Load-Deflection Relationship. The load-deflection curves at midspan of the tested beams are shown in Figures 7 and 8. In general, two major stages were observed. First, a linear branch with a steep slope was noticed, which related to the uncracked condition of the beams, where only the GPC sustained all the applied loads. Secondly, when the cracking load achieved, a drop in the slop was observed, due to the progressive cracks of the beams and the almost linear segment was observed until failure, except sudden drop down in loads in every earlier crack formations, especially for reinforcement ratios $\rho_{\mathrm{f}}<\rho_{\mathrm{fb}}$.

The test results show that the ultimate load of both the GFRP-RGPC and CFRP-RGPCC beams increased with the reinforcement ratio. For the GFRP-RGPC beams, the ultimate loads of the G02-GPC50 and G03-GPC50 beams increased, respectively, by $73.3 \%$ and $152.6 \%$ compared with that of the G01-GPC50 beam, as shown in Figure 7(a). For the CFRP-RGPC beams, the ultimate loads of the C02GPC50 and C03-GPC50 beams increased, respectively, by $36.9 \%$ and $50.9 \%$ compared with that of the C01-GPC50 beam as shown in Figure 7(b).

The test results also show that the deflection of the GFRP-RGPC and CFRP-RGPCC beams for the same load 


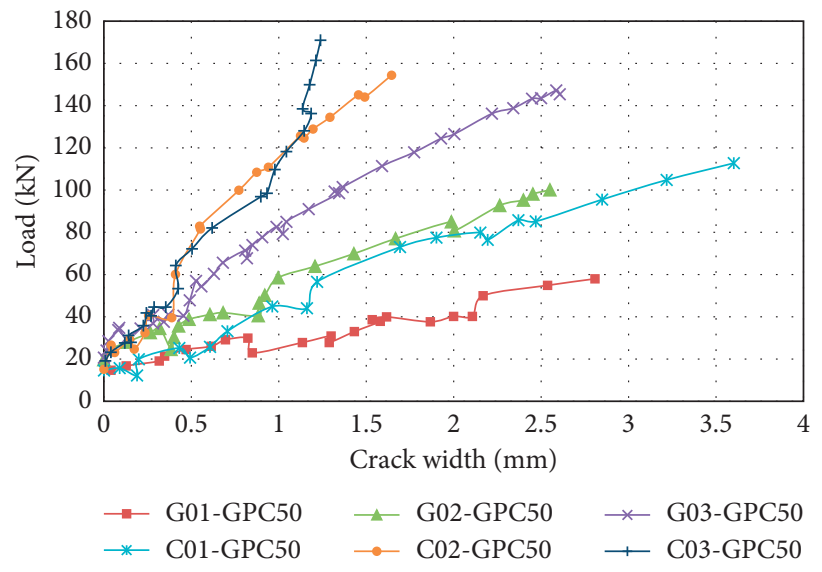

FIgURE 6: Load and crack width relationship.

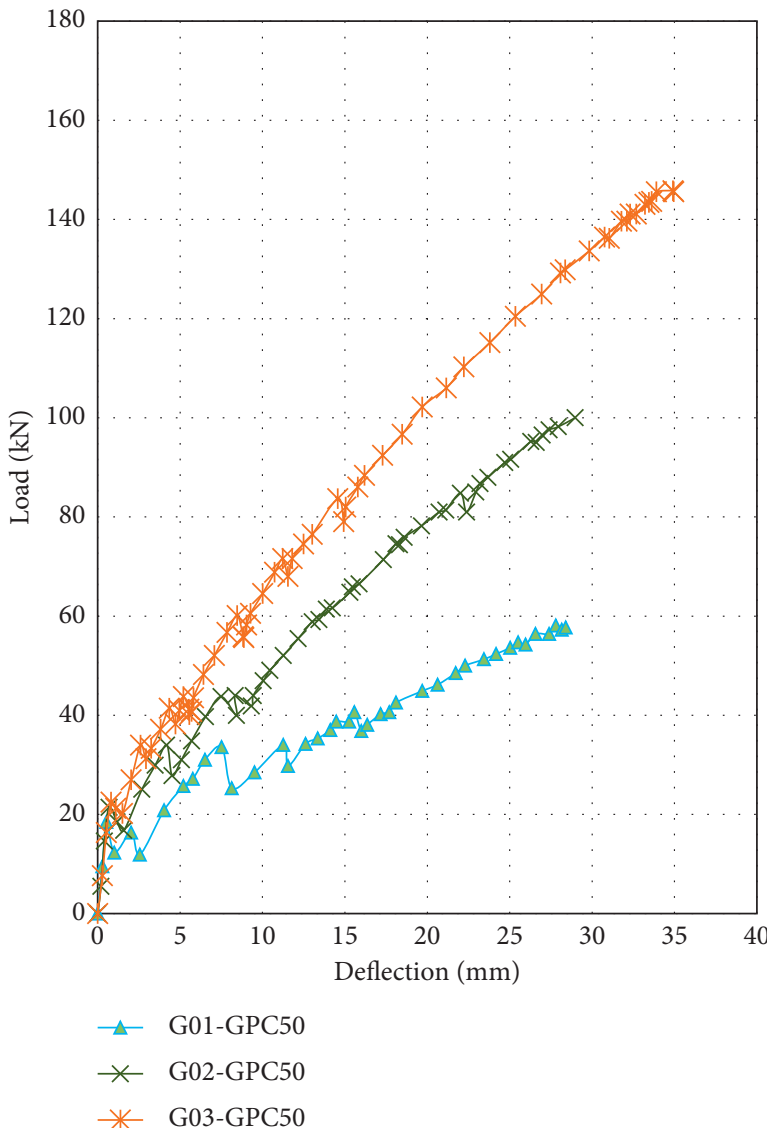

(a)

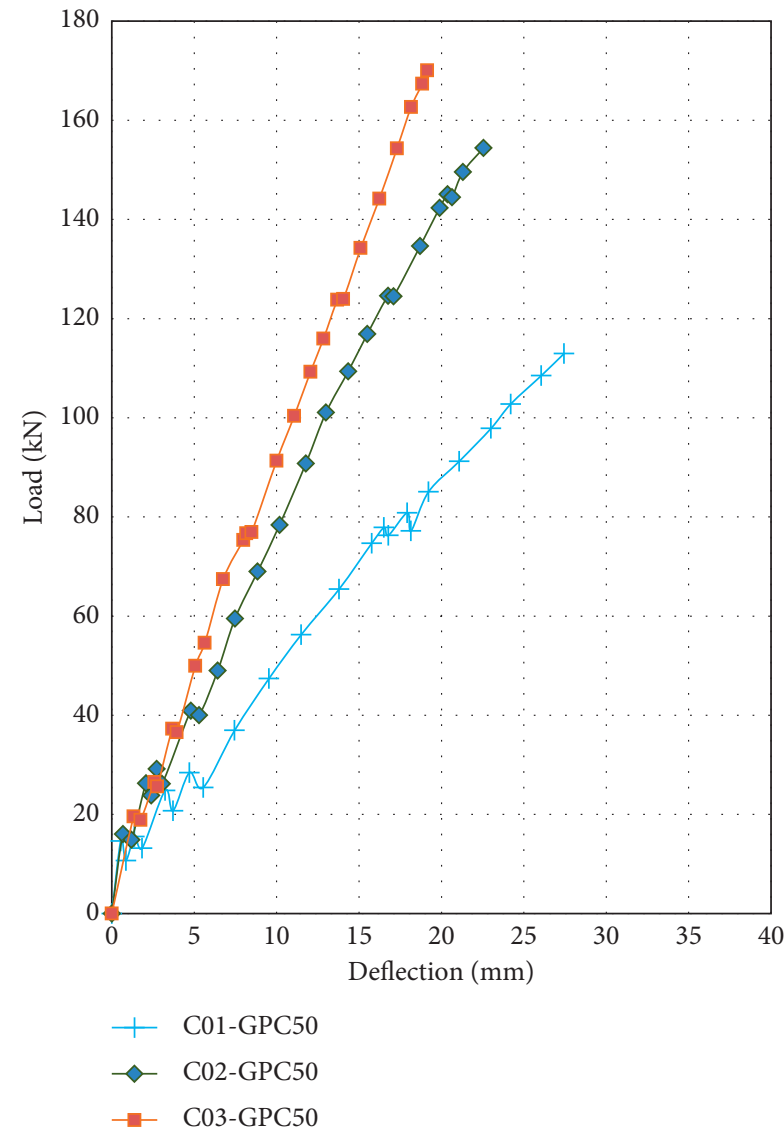

(b)

FIGURE 7: Load-deflection curves-reinforcement ratio effect. (a) G1-GFRP-RGPC. (b) G2-CFRP-RGPC.

level decreased with the increase in the reinforcement ratio. For the GFRP-RGPC beams, the deflection of the G01GPC50 beam was higher than that of the G02-GPC50 and G03-GPC50 beams, as shown in Figure 7(a). For the CFRPRGPC beams, the deflection of the C01-GPC50 beam was higher than that of the C02-GPC50 and C03-GPC50 beams, as shown in Figure 7(b).
The load-deflection curves of the test beams with different types of FRP bar are shown in Figure 8. For the same reinforcement ratio condition, the ultimate load capacity of CFRP-RGPC beams was higher than that of GFRP-RGPC, and this is due to the excessive tensile strength provided by CFRP bars. The ultimate load of C01-GPC50, C02-GPC50, and C02-GPC50 beams was higher than that of G01-GPC50, 


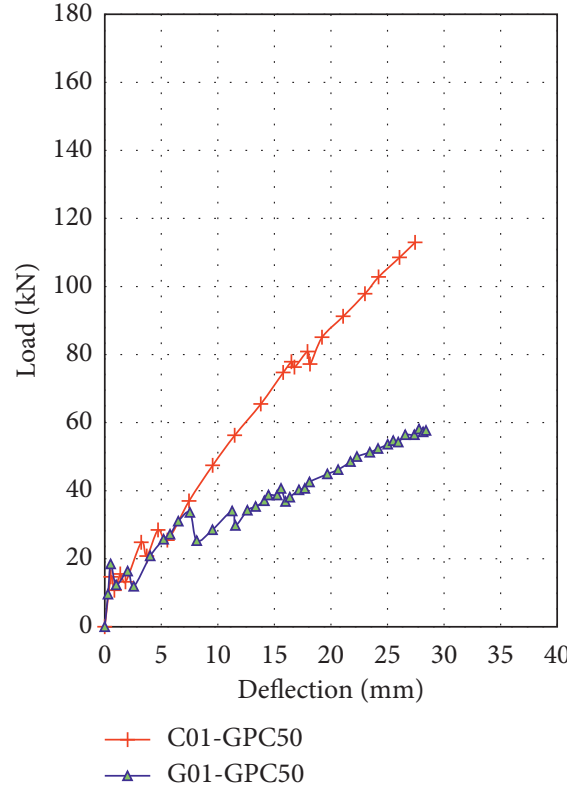

(a)

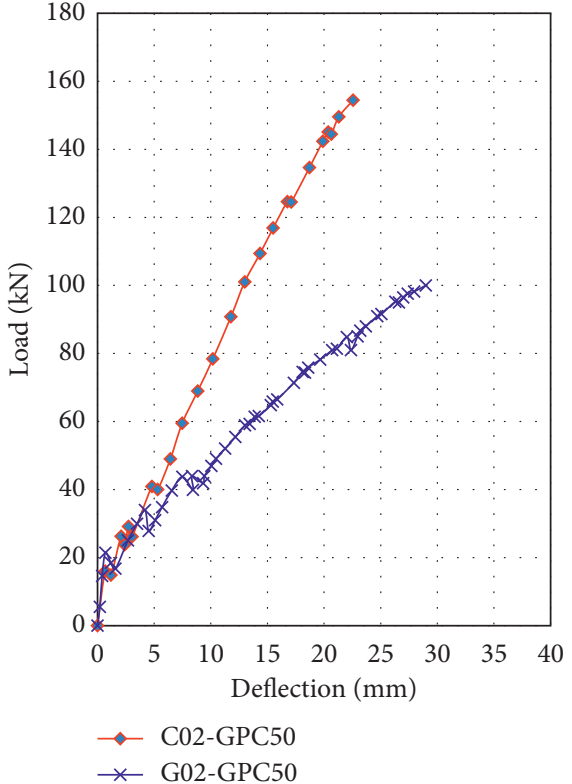

(b)



(c)

Figure 8: Load-deflection curves-FRP type effect. (a) $\rho_{\mathrm{f}}<\rho_{\mathrm{fb}}$. (b) $\rho_{\mathrm{fb}}<\rho_{\mathrm{f}}<1.4 \rho_{\mathrm{fb}}$. (c) $\rho_{\mathrm{f}}>1.4 \rho_{\mathrm{fb}}$.

G02-GPC50, and G02-GPC50 beams by 95.3\%, 54.1\%, and $16.5 \%$, respectively. These results indicate that the beams with the lower reinforcement ratios were more affected by the type of FRP bars because the tension failure dramatically depends on the tensile strength of the FRP bar. Moreover, the results also show that the deflection in GFRP-RGPC beams was higher than that in GFRP-RGPC beams for the same corresponding load level, and this is due to the higher ultimate strain in GFRP bars.

The effect of reinforcement ratio on the ultimate load and deflection at a load level of $50 \mathrm{kN}$ are shown in Figure 9. Lower reinforcement ratio $\left(\rho_{\mathrm{f}} / \rho_{\mathrm{fb}}=1.15\right)$ for CFRP-
RGPC beams is required to achieve the same load-carrying capacity, for example, $(140 \mathrm{kN})$ rather than $\left(\rho_{\mathrm{f}} / \rho_{\mathrm{fb}}=2.05\right)$ for GFRP-RGPC beams, as shown in Figure 9(a). For the same reinforcement ratio, the deflection in GFRP-RGPC beams was higher than that in CFRP-RGPC beams, while the difference was more obvious for lower reinforcement ratio rather than higher reinforcement ratio, as shown in Figure 9(b).

3.3. Strain in Longitudinal Reinforcement and Geopolymer Concrete. Load-strain curves for the tested beam specimens are shown in Figure 10. The strain in FRP bars and GPC at 


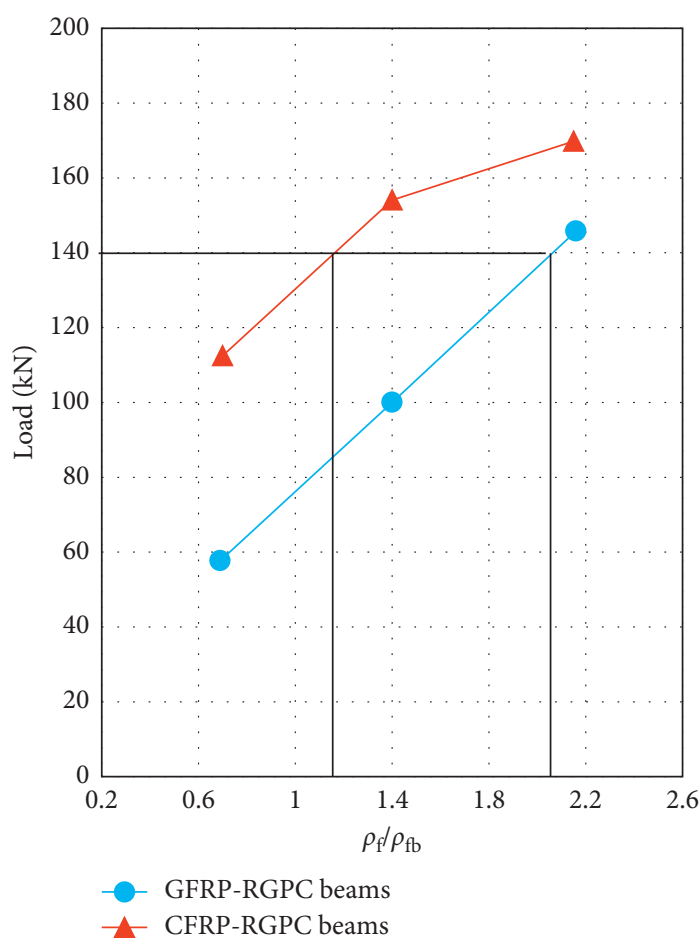

(a)

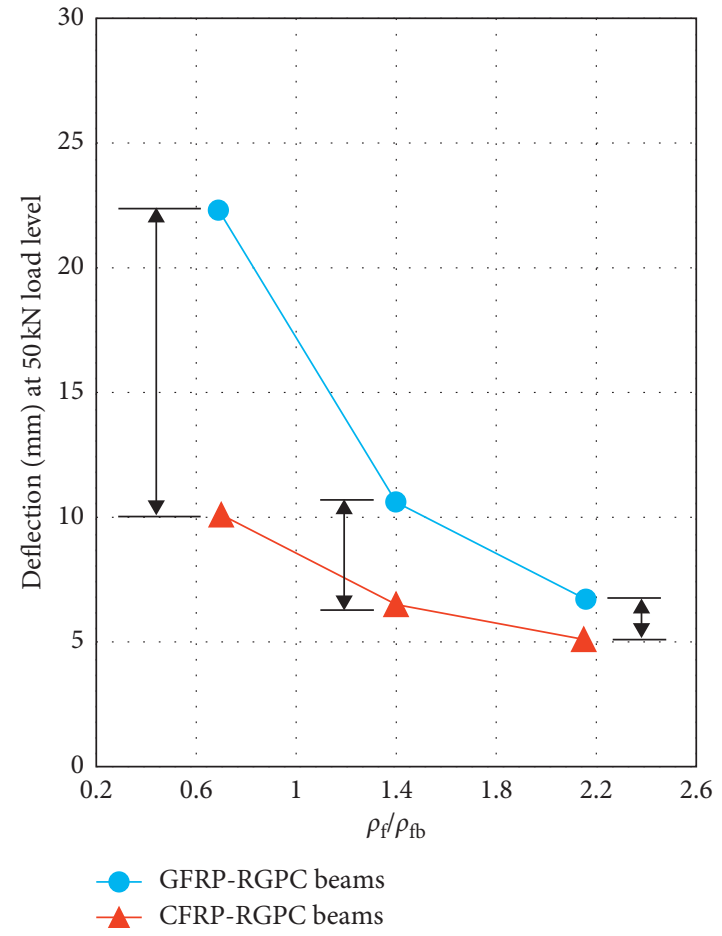

(b)

Figure 9: Reinforcement ratio effect on (a) ultimate load and (b) deflection.

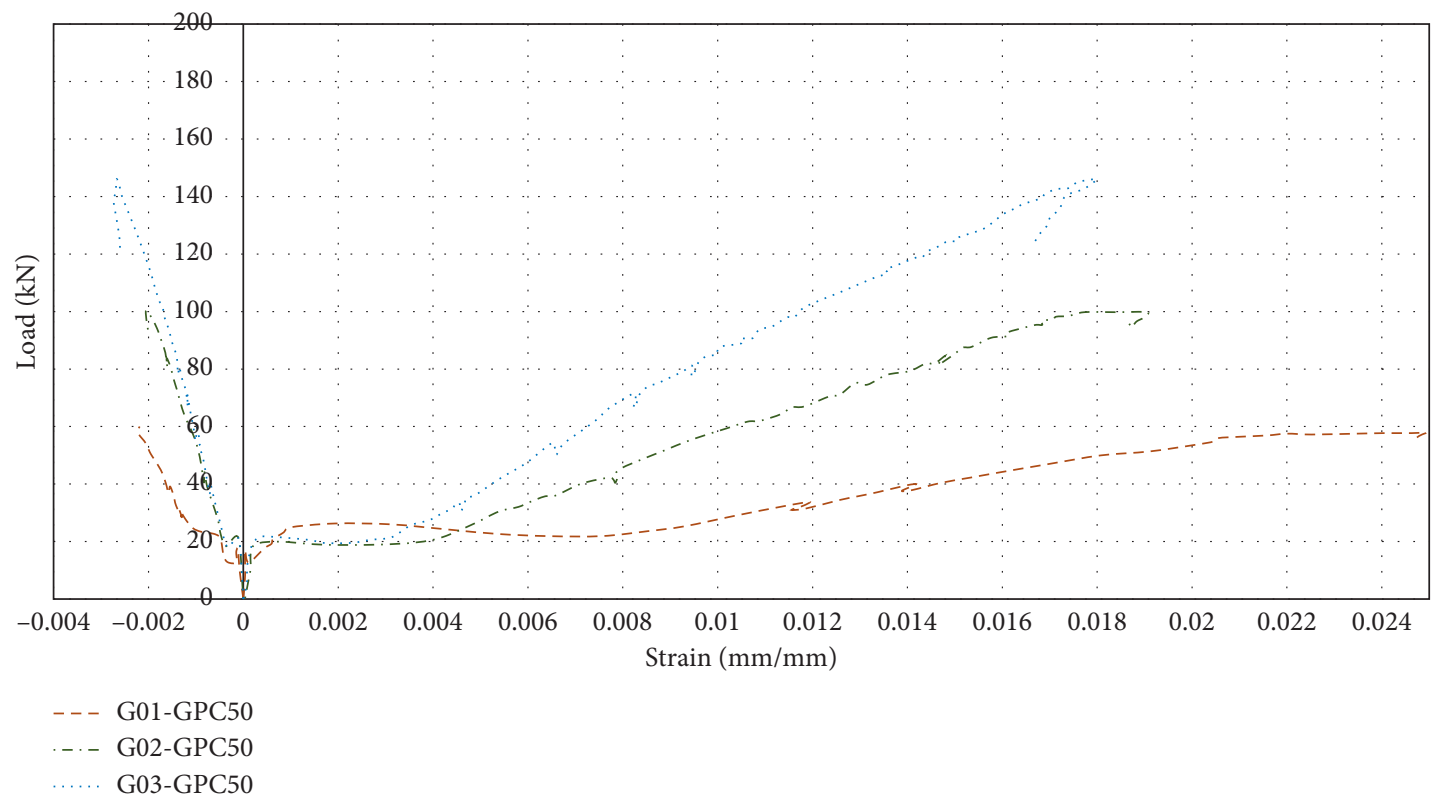

(a)

FIgURE 10: Continued. 


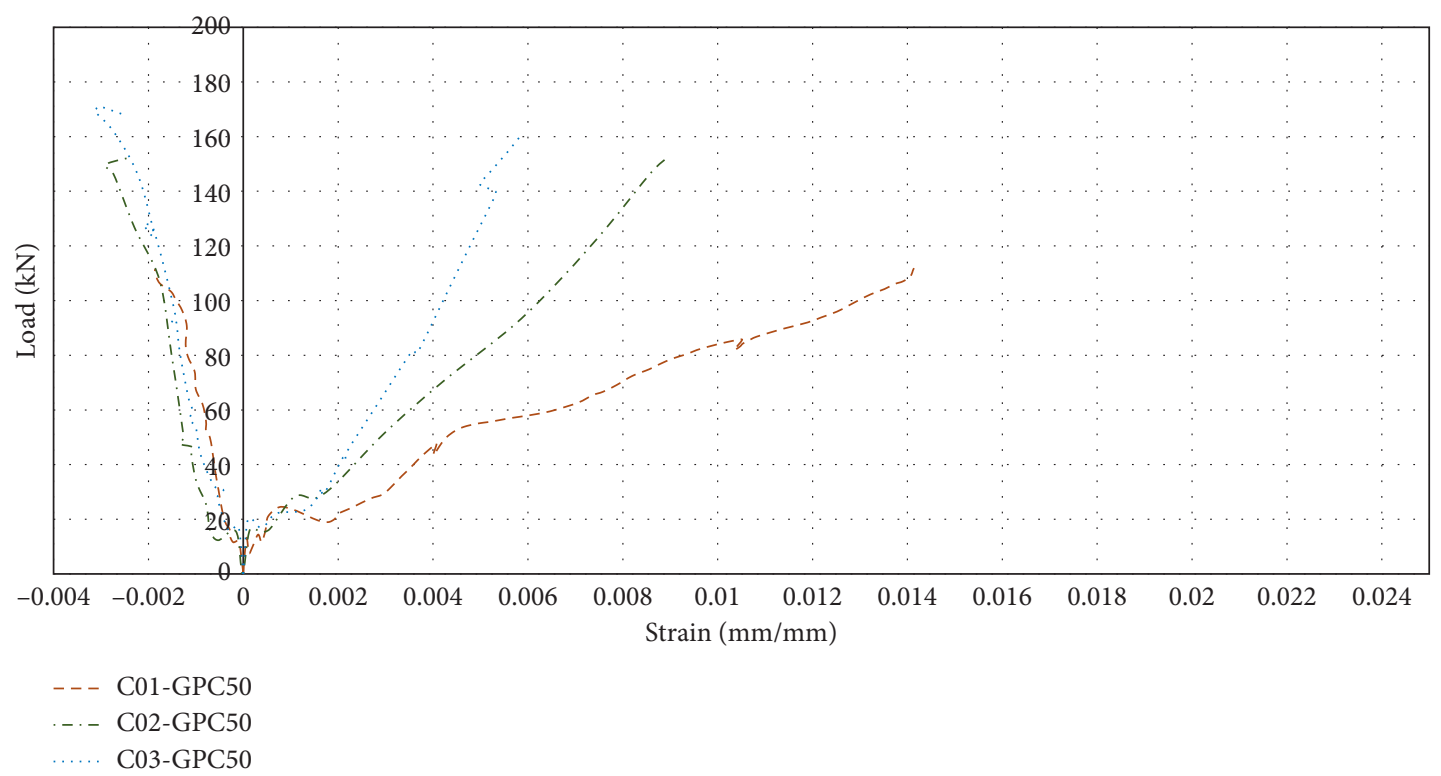

(b)

FIGURE 10: Load-strain curves. (a) G1-GFRP-RGPC. (b) G2-CFRP-RGPC.

the top surface was measured at the midspan of the specimens, and the positive and negative strain values on curves represent the strains in FRP and GPC, respectively. At first, the tested beam specimens shared almost the same small increase of linear strain segment in both FPR bars and PGC with the applied load until the initial crack load. Secondly, a rapid strain increase and the almost stable load were observed after the initial crack formation. Finally, the almost linear segment of load-strain curves was noticed until failure in FRP bars and a parabolic segment in GPC. Overall, the effect of the process of crack formation on strain-curves in both FRP and GPC can be noticed.

Strain in FRP and GPC and failure modes are in great relation. For G01-GPC50 and C01-GPC50 beams, the strain in FRP bars almost reached the ultimate strain while the strains in GPC did not reach the ultimate strain, which indicates a tension failure mode. For G02-GPC50 beam, the strain in FRP bar and GPC is near the ultimate strain, which indicates balanced failure. For C02-GPC50, G03-GPC50, and C03-GPC50 beams, the strain in concrete almost reached the ultimate strain but not in FRP bars, which indicates the compression failure mode.

\section{Theoretical Prediction}

In this study, the theoretical flexural capacities $\left(M_{\mathrm{u}}\right)$ and ultimate deflection $\left(\Delta_{\mathrm{u}}\right)$ of GFRP-RGPC and CFRP-RGPC beams were computed based on the equations provided by ACI 440.1R-15 [11] and CSA S806-12 [22] and compared with experimental flexural capacities $\left(M_{\mathrm{u}-\exp }\right)$ and deflection $\left(\Delta_{\mathrm{u}-\exp }\right)$ results.
4.1. Equations Provided by ACI 44.1R-15 and CSA S806-12. According to ACI 440.1R-15 [11], the moment of resistance of a concrete beam reinforced with FRP bars can be determined based on strain compatibility, internal force equilibrium, and the controlling mode of failure (tension failure or compression failure). The predicted failure mode can be determined by comparing the reinforcement ratio $\rho_{\mathrm{f}}$ (equation (1)) to the balanced reinforcement ratio $\rho_{\mathrm{fb}}$ (equation (2)), which is the rate for indicating concrete crushing and FRP rapture, as follows:

$$
\rho_{\mathrm{f}}=\frac{A_{\mathrm{f}}}{b d},
$$

where $A_{\mathrm{f}}$ is the area of FRP bar, $b$ is the width of the rectangular cross section, and $d$ is the distance from extreme compression fibre to the centroid of FRP bars.

$$
\rho_{\mathrm{fb}}=0.85 \beta_{1} \frac{f_{\mathrm{c}}^{\prime}}{f_{\mathrm{fu}}} \frac{E_{\mathrm{f}} \varepsilon_{\mathrm{cu}}}{E_{\mathrm{f}} \varepsilon_{\mathrm{cu}}+f_{\mathrm{fu}}},
$$

where $f_{\mathrm{c}}^{\prime}$ is the specified compressive strength of concrete, $f_{\mathrm{fu}}$ is the ultimate tensile stress of FRP bars, $E_{\mathrm{f}}$ is the elastic modulus of FRP, $\varepsilon_{\mathrm{cu}}$ is the ultimate strain in concrete taken equal to 0.003 , and the factor $\beta_{1}$ can be calculated as follows:

$$
\beta_{1}=0.85-\frac{0.05\left(f_{\mathrm{c}}^{\prime}-28\right)}{7} \geq 0.65 .
$$

First, if $\rho_{\mathrm{f}}>\rho_{\mathrm{fb}}$, the beam is considered as overreinforced, the controlling limit state is crushing of concrete, and the moment of resistance $(M)$ can be calculated as follows:

$$
M=\rho_{\mathrm{f}} f_{\mathrm{f}} b d^{2}\left(1-0.59 \frac{\rho_{\mathrm{f}} f_{\mathrm{f}}}{f_{\mathrm{c}}^{\prime}}\right),
$$


where $f_{\mathrm{f}}$ is the tensile strength of the FRP bars and can be calculated using the following equation:

$$
f_{\mathrm{f}}=\sqrt{\frac{\left(E_{\mathrm{f}} \varepsilon_{\mathrm{cu}}\right)^{2}}{4}+\frac{0.85 \beta_{1} f_{\mathrm{c}}^{\prime}}{\rho_{f}} E_{\mathrm{f}} \varepsilon_{\mathrm{cu}}}-0.5 E_{\mathrm{f}} \varepsilon_{\mathrm{cu}} \leq f_{\mathrm{fu}} .
$$

Secondly, if $\rho_{\mathrm{fb}}<\rho_{\mathrm{f}}<1.4 \rho_{\mathrm{fb}}$, this particular condition can described by a transition zone, when crashing of concrete followed by the rapture of FRP bar (balanced) failure. Finally, if $\rho_{\mathrm{f}}<\rho_{\mathrm{fb}}$, the beam is considered as underreinforced, the controlling limit is FRP rapture, and $M$ can be estimated using the following equation

$$
\begin{aligned}
M & =A_{\mathrm{f}} f_{\mathrm{fu}}\left(d-\frac{\beta_{1} c}{2}\right), \\
\beta_{1} c & =\frac{A_{\mathrm{f}} f_{\mathrm{f}}}{0.85 f_{\mathrm{c}}^{\prime} b},
\end{aligned}
$$

where $c$ is the distance from the extreme compression fibre to the neutral axis.

For deflection calculation, ACI 440.1R-15 [11] depends on the effective moment of inertia $\left(I_{\mathrm{e}}\right)$ in cracked RFP reinforced concrete beams, which can be calculated as follows:

$$
I_{\mathrm{e}}=\frac{I_{\mathrm{cr}}}{1-\gamma\left(M_{\mathrm{cr}} / M_{\mathrm{a}}\right)^{2}\left[1-\left(I_{\mathrm{cr}} / I_{\mathrm{g}}\right)\right]},
$$

where $I_{\mathrm{cr}}$ is the cracked moment of inertia, $I_{\mathrm{g}}$ is the gross moment of inertia, $M_{\mathrm{cr}}$ is the cracking moment, and $M_{\mathrm{a}}$ is the maximum service moment, and factor $\gamma$, which depends on loading and boundary conditions, for a simply supported beam with four-point loading can be calculated as follows:

$$
\gamma=\frac{3(a / L)-16\left(M_{\mathrm{cr}} / M_{\mathrm{a}}\right)(a / L)^{3}+12(a / L)^{3}}{3(a / L)-4(a / L)^{3}} .
$$

Once $I_{\mathrm{e}}$ is calculated, midspan deflection $\Delta$ can be calculated using solid mechanics formula; here, for four-point bending, equation (9) can be used.

$$
\Delta=\frac{(P a / 2)}{24 E_{\mathrm{c}} I_{\mathrm{e}}}\left(3 L^{2}-4 a^{2}\right),
$$

where $P$ is the service load, which is taken equal to 0.40 times the ultimate experimental loads as suggested by Wang and Belarbi [32], $L$ is the span length, $a$ is the shear-span length, and $E_{\mathrm{c}}$ is the elastic modulus of concrete.

According to CSA S806-12 [22], FRP-reinforced concrete beams were preferred to be designed in such a way that the controlling limit state is crushing of concrete, and $\epsilon_{\mathrm{cu}}$ is taken equal to 0.0035 , and it also depends on strain compatibility and internal force equilibrium. Balanced reinforcement ratio $\rho_{\mathrm{fb}}$ can be calculated from equation (10), while factors $\alpha_{1}$ and $\beta_{1}$ can be calculated from equations (11) and (12), respectively:

$$
\begin{aligned}
& \rho_{\mathrm{fb}}=\alpha_{1} \beta_{1} \frac{f_{\mathrm{c}}^{\prime}}{f_{\mathrm{fu}}} \frac{E_{\mathrm{f}} \varepsilon_{\mathrm{cu}}}{E_{\mathrm{f}} \varepsilon_{\mathrm{cu}}+f_{\mathrm{fu}}}, \\
& \alpha_{1}=0.85-0.0015 f_{\mathrm{c}}^{\prime} \geq 0.67, \\
& \beta_{1}=0.97-0.0025 f_{\mathrm{c}}^{\prime} \geq 0.67 .
\end{aligned}
$$

The moment of resistance $(M)$ can be calculated from equation (13), and the stress in the FRP bar $f_{\mathrm{f}}$ can be calculated by using equation (14), where the neutral axis $c$ can be determined by using equation (15):

$$
\begin{gathered}
M=\rho_{\mathrm{f}} f_{\mathrm{f}} b d^{2}\left(1-\frac{\rho_{\mathrm{f}} f_{\mathrm{f}}}{2 \alpha_{1} f_{\mathrm{c}}^{\prime}}\right), \\
f_{\mathrm{f}}=A_{\mathrm{f}} E_{\mathrm{f}} \frac{\varepsilon_{\mathrm{cu}}(d-c)}{c}<f_{\mathrm{fu}}, \\
\alpha_{1} \beta_{1} f_{\mathrm{c}}^{\prime} b c-A_{\mathrm{f}} E_{\mathrm{f}} \frac{\varepsilon_{\mathrm{cu}}(d-c)}{c}=0 .
\end{gathered}
$$

The CSA S806-12 [22] states that the deflection $\Delta$ shall be computed by methods based on the integration of the curvature at sections along the span. This can be an intensive calculation process subject to human error, so the code also provides closed-form equations for the common loading and boundary conditions. For four-point loading, the deflection $\Delta$ can be calculated as follows:

$$
\Delta=\frac{(P / 2) L^{3}}{24 E_{\mathrm{c}} I_{\mathrm{cr}}}\left(3 \frac{a}{L}-4\left(\frac{a}{L}\right)^{3}-8 \eta\left(\frac{L_{\mathrm{g}}}{L}\right)^{3}\right),
$$

where $L_{\mathrm{g}}$ is the uncracked length in half of the beam and factor $\eta$ can be calculated as follows:

$$
\eta=1-\frac{I_{\mathrm{cr}}}{I_{\mathrm{g}}}
$$

4.2. Comparing Experimental Results with Theoretical Predictions. The predicted moment of resistance $(M)$ and deflection $(\Delta)$ at service load, calculated by ACI 440.1R-15 [11], CSA S806-12 [22], and experimental, are compared as shown in Table 6 . The prediction equations provided by ACI 440.1R-15 [11] and CSA S806-12 [22] underestimated the flexural capacity of RGPC beams by $70.3 \%$ and $78.1 \%$, respectively. ACI 440.1R-15 [11] predicted more accurately for GFRP-RGPC beams (73.7\%) than that for CFRP-RGPC beams (66.3\%), while CSA S806-12 [22] predicted a bit better (82.6\%) for GFRP-RGPC beams than (73.7\%) for CFRPRGPC beams.

On the other hand, the prediction equations provided by ACI 440.1R-15 [11] and CSA S806-12 [22] also overestimated the midspan deflection at service load of GFRPRGPC beams, while the values are in the closest form for CFRP-RGPC beams. Figure 11 shows a graphical comparison for the moment of resistance provided by ACI 440.1R15 [11], CSA S806-12 [22], and experimental results. 
TABLE 6: Theoretical prediction and experimental result-A Comparison.

\begin{tabular}{|c|c|c|c|c|c|c|c|c|c|c|c|}
\hline \multirow[b]{2}{*}{ Group } & \multirow[b]{2}{*}{ Specimen ID } & \multicolumn{3}{|c|}{ Moment resistance } & \multicolumn{3}{|c|}{ Deflections at service load } & \multicolumn{4}{|c|}{ Comparisons } \\
\hline & & $\begin{array}{c}M_{\exp } \\
(\mathrm{kN} \cdot \mathrm{m})\end{array}$ & $\begin{array}{l}M, \mathrm{ACI} \\
(\mathrm{kN} \cdot \mathrm{m})\end{array}$ & $\begin{array}{c}M, \mathrm{CSA} \\
(\mathrm{kN} \cdot \mathrm{m})\end{array}$ & $\begin{array}{c}\Delta_{\exp } \\
(\mathrm{mm})\end{array}$ & $\begin{array}{l}\Delta \mathrm{ACI} \\
(\mathrm{mm})\end{array}$ & $\begin{array}{l}\Delta \mathrm{CSA} \\
(\mathrm{mm})\end{array}$ & $M, \mathrm{AC}$ & $\mathrm{p}(\%)$ & $M, \mathrm{CS}$ & p $(\%)$ \\
\hline \multirow{3}{*}{ G1 } & G01-GPC50 & 23.08 & 19.02 & 18.98 & 3.81 & 13.09 & 13.13 & 82.4 & & 82.2 & \\
\hline & G02-GPC50 & 40.00 & 31.44 & 37.03 & 5.63 & 11.84 & 14.41 & 78.6 & 74.2 & 92.6 & 82.6 \\
\hline & G03-GPC50 & 58.32 & 35.91 & 42.62 & 4.42 & 9.87 & 11.42 & 61.6 & & 73.1 & \\
\hline \multirow{4}{*}{ G2 } & C01-GPC50 & 45.00 & 28.85 & 28.72 & 3.32 & 6.19 & 6.51 & 64.1 & & 63.8 & \\
\hline & C02-GPC50 & 61.64 & 40.55 & 47.66 & 6.25 & 5.51 & 6.15 & 65.8 & 66.3 & 77.3 & 73.7 \\
\hline & C03-GPC50 & 67.92 & 46.89 & 54.37 & 5.37 & 4.38 & 4.80 & 69.1 & & 80.1 & \\
\hline & & & & & & & Avg. (\%) & \multicolumn{2}{|c|}{70.3} & \multicolumn{2}{|c|}{78.1} \\
\hline
\end{tabular}

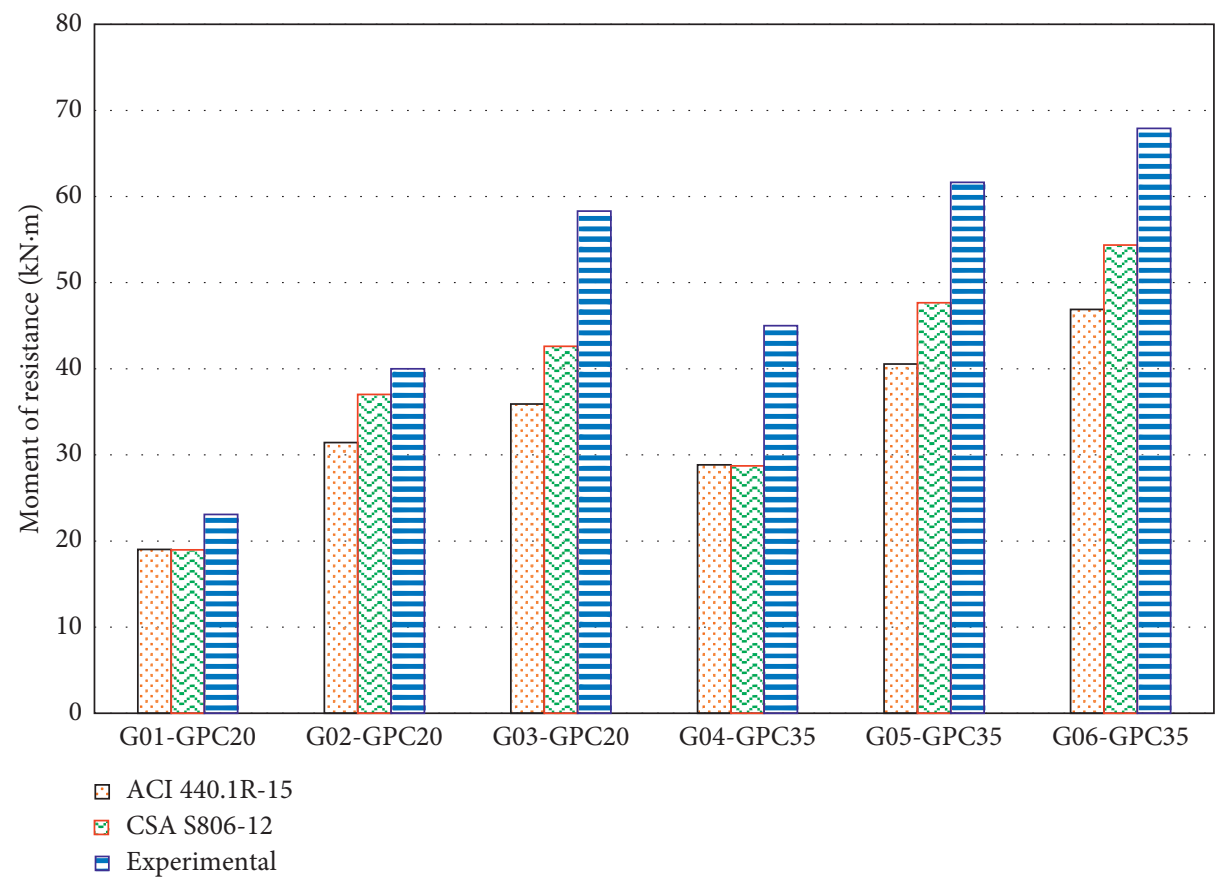

FIgURE 11: Moment of resistance-graphical comparison.

TABLE 7: Normalised flexural capacity of GFRP-RGPC, CFRP-RGPC, and GFRP-ROPC beams.

\begin{tabular}{lccccc}
\hline Reference & Beam & $\rho_{\mathrm{f}}$ & Concrete type & FRP type & Normalised flexural capacity $\left(M_{\mathrm{u}} / f_{\mathrm{c}}^{\prime} \cdot b d^{2}\right)$ \\
\hline \multirow{2}{*}{ Current study } & G02-GPC50 & $1.39 \rho_{\mathrm{fb}}$ & GPC & GFRP & 42.44 \\
& C02-GPC50 & $1.40 \rho_{\mathrm{fb}}$ & GPC & CFRP & 124.71 \\
\hline \multirow{2}{*}{ Maranan et al. [20] } & GFRP-RGC-4-12.7 & $1.13 \%$ & GPC & GFRP & 47.7 \\
& GFRP-RGC-3-15.9 & $1.18 \%$ & GPC & GFRP & 54.3 \\
& GFRP-RGC-2-19.0 & $1.00 \%$ & GPC & GFRP & 49.6 \\
\multirow{2}{*}{ Toutanji and Saafi [33] } & GB3-1 & $1.10 \%$ & OPC & GFRP & 44.6 \\
& GB3-2 & $1.10 \%$ & OPC & GFRP & 47.3 \\
\multirow{2}{*}{ Benmokrane and Masmoudi [34] } & ISO1 & $1.10 \%$ & OPC & GFRP & 35.1 \\
& ISO2 & $1.10 \%$ & OPC & GFRP & 36.7 \\
\hline Benmokrane et al. [35] & ISO30-2 & $1.01 \%$ & OPC & GFRP & 35.9 \\
\hline
\end{tabular}

4.3. Comparison between GFRP-RGPC, CFRP-RGPC, and GFRP-ROPC Beams. The comparison between the normalised flexural capacity of GFRP-RGPC, CFRP-RGPC, and GFRP-ROPC beams is shown in Table 7. The GFRP-RGPC and CFRP-RGPC beams that were considered in the study have nearly similar concrete strengths and amount and type of reinforcements. In general, the bending-moment capacities of the tested beams GFRP-RGPC beams were higher than the
GFRP-ROPC beams. This is due to the enhanced mechanical properties of the geopolymer concrete compared with normal concrete and the provision of lateral ties within the constant bending-moment zone that provided confinement according to the previous studies. The higher concrete compressive strength is used in this study compared with the previous ones. On the other hand, the difference in normalised flexural capacity was noticed between CFRG-RGPC (42.44) and GFRP- 
RGPC (124.71), due to the higher tensile stress of CFRP bars and difference in beams' cross section.

\section{Conclusions}

The flexural capacity and behaviour of RGPC beams with GFRP and CFRP bars were investigated under four-point bending test. Based on the experimental results, the following conclusions were made:

(i) More crack formations were observed in the CFRP-RGPC beams than in the GFRP-RGPC beams, and the crack width in the GFRP-RGPC beams was wider than that in the CFRP-RGPC beams.

(ii) Beams with lower reinforcement ratios experienced a fewer number of cracks and a higher value of crack width, while the beams with higher reinforcement ratio experienced numerous cracks and less value of crack width.

(iii) The increase in reinforcement ratio had a significant effect on first cracking load and ultimate load; the ultimate load of GFRP-RGPC and CFRPRGPC beam increased by $152.6 \%$ and $50.9 \%$, respectively, for the same increase in reinforcement ratio.

(iv) The ultimate load capacity of CFRP-RGPC beams was higher than that of GFRP-RGPC, for different reinforcement conditions of $\rho_{\mathrm{f}}<\rho_{\mathrm{fb}}, \rho_{\mathrm{fb}}<\rho_{\mathrm{f}}<1.4 \rho_{\mathrm{fb}}$, and $\rho_{\mathrm{f}}>1.4 \rho_{\mathrm{fb}}$ by $95.3 \%, 54.1 \%$, and $16.5 \%$, respectively, and this is due to the excessive tensile strength provided by CFRP bars.

(v) Beams with the lower reinforcement ratios were more affected by the type of FRP bars because the tension failure dramatically depends on the tensile strength of the FRP bar. The deflection in GFRPRGPC beams was higher than that in CFRP-RGPC beams for the same corresponding load level, and this is due to the lower modulus of elasticity of GFRP than CFRP bars.

(vi) Based on the findings of this study, CFRP bars are considered better than GFRP bars in GPC beams because for the same reinforcement ratio, the ultimate load for CFRP-RGPC beams was higher than that for GFRP-RGPC beams. Same reinforcement ratio achieved with less cross section of CFRP-RGPC beams means minimising the dead load. CFRP-RGPC beams recorded the lower value of crack width.

(vii) ACI 440.1R-15 and CSA S806-12 underestimated the moment of resistance of RGPC beams by $70.3 \%$ and $78.1 \%$, respectively. ACI 440.1R-15 predicted more accurately for GFRP-RGPC beams (73.7\%) than that for CFRP-RGPC beams $(66.3 \%)$, while CSA S806-12 predicted a bit better $(82.6 \%)$ for GFRP-RGPC beams than (73.7\%) for CFRP-RGPC beams. (viii) ACI 440.1R-15 and CSA S806-12 overestimated the midspan deflection at service load of GFRPRGPC beams, while the values are in the closest form for CFRP-RGPC beams.

The implications of this research for construction practice and research are as follows:

(i) Applications of GPC reinforced with FRP bars can be an ideal choice in civil infrastructural applications since conventional cement production is highly energy-intensive and causes global environmental issues. Because FR bars are noncorrosive and nonmagnetic, the problem of steel corrosion and the electromagnetic interface can be eliminated. Additionally, FRP bars have excessive tensile-stress, making them proper to use as a structural reinforcement.

(ii) Based on the findings of this study, the following suggestions and recommendations may be considered for future studies: studying the flexural behaviour of geopolymer concrete beams with different types of FRP bars (GFRP and AFRP), shear strength and behaviour of GPC beams reinforced with FRP bars and because of the difference in property of GPC and OPC, more comparison could be established in future studies.

\section{Data Availability}

The data used to support the findings of this study are included within the article.

\section{Conflicts of Interest}

The authors declare that there are no conflicts of interest regarding the publication of this paper.

\section{References}

[1] P. K. Mehta, "Reducing the environmental impact of concrete," Concrete International, vol. 23, no. 10, pp. 61-66, 2001.

[2] D. Hardjito and B. V. Rangan, Development and Properties of Low-Calcium Fly Ash-Based Geopolymer Concrete, Faculty of Engineering, Curtin University of Technology, GCI, Perth, Australia, 2005.

[3] R. McCaffrey, "Climate change and the cement industry," in Global Cement and Lime Magazine (Environmental Special Issue), pp. 15-19, 2002.

[4] K. M. Liew, A. O. Sojobi, and L. W. Zhang, "Green concrete: prospects and challenges," Construction and Building Materials, vol. 156, pp. 1063-1095, 2017.

[5] D. Hardjito and S. E. Wallah, "Introducing fly ash-based geopolymer concrete manufacture and engineering properties," in Proceedings of the 30th Conference on Our World in Concrete \& Structures, Singapore, August 2005.

[6] N. A. Lloyd and B. V. Rangan, "Geopolymer concrete with fly ash," in Proceedings of the Second International Conference on sustainable construction Materials and Technologies, Ancona, Italy, June 2010.

[7] W. Ferdous, A. Manalo, G. Van Erp, T. Aravinthan, and K. Ghabraie, "Evaluation of an innovative composite railway 
sleeper for a narrow-gauge track under static load," Journal of Composites for Construction, vol. 22, no. 2, Article ID 04017050, 2018.

[8] W. Ferdous, Y. Bai, A. D. Almutairi, S. Satasivam, and J. Jeske, "Modular assembly of water-retaining walls using GFRP hollow profiles: components and connection performance," Composite Structures, vol. 194, pp. 1-11, 2018.

[9] W. Ferdous, Y. Bai, T. D. Ngo, A. Manalo, and P. Mendis, "New advancements, challenges and opportunities of multistorey modular buildings-a state-of-the-art review," Engineering Structures, vol. 183, pp. 883-893, 2019.

[10] L. W. Zhang, A. O. Sojobi, and K. M. Liew, "Sustainable CFRP-reinforced recycled concrete for cleaner eco-friendly construction," Journal of Cleaner Production, vol. 233, pp. $56-75,2019$.

[11] ACI 440.1R-15, Guide for the Design and Construction of Concrete Reinforced with Fiber Reinforced Polymers (FRP) Bars, American Concrete Institute, Farmington Hills, MI, USA, 2015.

[12] S. Kumaravel and S. Thirugnanasambandam, "Flexural behaviour of reinforced low calcium fly ash based geopolymer concrete beam," Global Journal of Research in Engineering, vol. 13, no. 8, 2013.

[13] S. Kumaravel and S. Thirugnanasambandam, "Flexural behaviour of geopolymer concrete beams," International Journal of Advanced Engineering Research and Studies, vol. 4, p. 6, 2013.

[14] C. K. Madheswaran, P. S. Ambily, N. P. Rajamane, and G. Arun, "Studies on flexural behaviour of reinforced geopolymer concrete beams with lightweight aggregates," International Journal of Civil and Structural Engineering, vol. 4, no. 3, p. 295, 2014.

[15] A. Hutagi and R. Khadiranaikar, "Flexural behavior of reinforced geopolymer concrete beams," in Proceedings of the 2016 International Conference on Electrical, Electronics, and Optimization Techniques (ICEEOT), pp. 3463-3467, Chennai, India, March 2016.

[16] B. S. C. Kumar and K. Ramesh, "Flexural behavior of reinforced geopolymer concrete beams with GGBS and metakaolin," Global Journal of Engineering Science and Researches, vol. 4, 2017.

[17] M. K. Thangamanibindhu and D. S. R. Murthy, "Flexural behavior of reinforced geopolymer concrete beams partially replaced with recycled coarse aggregates," International Journal of Civil Engineering and Technology (IJCIET), vol. 6, no. 7, pp. 13-23, 2015.

[18] R. Abraham, S. Raj, and V. Abraham, "Strength and behaviour of geopolymer concrete beams," International Journal of Innovative Research in Science, Engineering and Technology, vol. 2, no. 1, pp. 159-166, 2013.

[19] G. B. Maranan, A. C. Manalo, B. Benmokrane, W. Karunasena, and P. Mendis, "Evaluation of the flexural strength and serviceability of geopolymer concrete beams reinforced with glass-fibre-reinforced polymer (GFRP) bars," Engineering Structures, vol. 101, pp. 529-541, 2015.

[20] G. B. Maranan, A. C. Manalo, W. Karunasena, B. Benmokrane, and P. Mendis, "Flexural response of GFRPreinforced geopolymer concrete beams," in Proceedings of the 27th Biennial National Conference of the Concrete Institute of Australia (Concrete 2015), pp. 287-296, Melbourne, Australia, August 2015.

[21] H. Q. Ahmed, D. K. Jaf, and S. A. Yaseen, "Flexural strength and failure of geopolymer concrete beams reinforced with carbon fibre-reinforced polymer bars," Construction and Building Materials, vol. 231, p. 117185, 2020.

[22] CSA S806-12, Design and Construction of Building Structures with Fiber-Reinforced Polymers, Canadian Standard Association (CSA), Ontario, Canada, 2012.

[23] ASTM C33, Standard Specification for Concrete Aggregates, ASTM International, West Conshohocken, PA, USA, 1999.

[24] ASTM C39/C39M, Standard Test Method for Compressive Strength of Cylindrical Concrete Specimens, ASTM International, West Conshohocken, PA, USA, 1999.

[25] ASTM C496/C496M, Standard Test Method for Splitting Tensile Strength of Cylindrical Concrete Specimens, ASTM International, West Conshohocken, PA, USA, 2004.

[26] ASTM C78/C78M, Standard Test Method for Flexural Strength of Concrete (Using Simple Beam with Third-Point Loading), ASTM International, West Conshohocken, PA, USA, 2013.

[27] ASTM C469/C469M, Standard Test Method for Static Modulus of Elasticity and Poisson's Ratio of Concrete in Compression, ASTM International, West Conshohocken, PA, USA, 2014.

[28] M. Ferdous, O. Kayali, and A. Khennane, "A detailed procedure of mix design for fly ash based geopolymer concrete," in Proceedings of the 2013 Asia-Pacific Conference on FRP in Structures (APFIS 2013), pp. 11-13, Melbourne, Australia, December 2013.

[29] S. V. Patankar, Y. M. Ghugal, and S. S. Jamkar, "Mix design of fly ash based geopolymer concrete," in Advances in Structural Engineering, pp. 1619-1634, Springer, New Delhi, India, 2015.

[30] D. Hardjito, S. E. Wallah, D. M. J. Sumajouw et al., "Factors influencing the compressive strength of fly ash-based geopolymer concrete," Civil Engineering Dimension, vol. 6, no. 2, pp. 88-93, 2004.

[31] A. Kirschner and H. Harmuth, "Investigation of geopolymer binders with respect to their application for building materials," Ceramics Silikaty, vol. 48, pp. 117-120, 2004.

[32] H. Wang and A. Belarbi, "Flexural behavior of fiber-reinforced-concrete beams reinforced with FRP rebars," in Proceedings of the SP-230: 7th International Symposium on FiberReinforced (FRP) Polymer Reinforcement for Concrete Structures, vol. 51, no. 230, pp. 895-914, Kansas City, MO, USA, November 2005.

[33] H. A. Toutanji and M. Saafi, "Flexural behavior of concrete beams reinforced with glass fiber-reinforced polymer (GFRP) bars," ACI Structural Journal, vol. 97, no. 5, pp. 712-719, 2000.

[34] B. Benmokrane and R. Masmoudi, "Flexural response of concrete beams reinforced with FRP reinforcing bars," $A C I$ Structural Journal, vol. 93, no. 1, pp. 46-55, 1996.

[35] B. Benmokrane, O. Chaallal, and R. Masmoudi, "Glass fibre reinforced plastic (GFRP) rebars for concrete structures," Construction and Building Materials, vol. 9, no. 6, pp. 353364, 1995. 


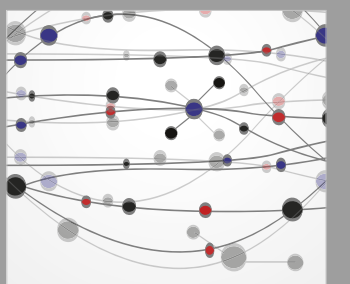

The Scientific World Journal
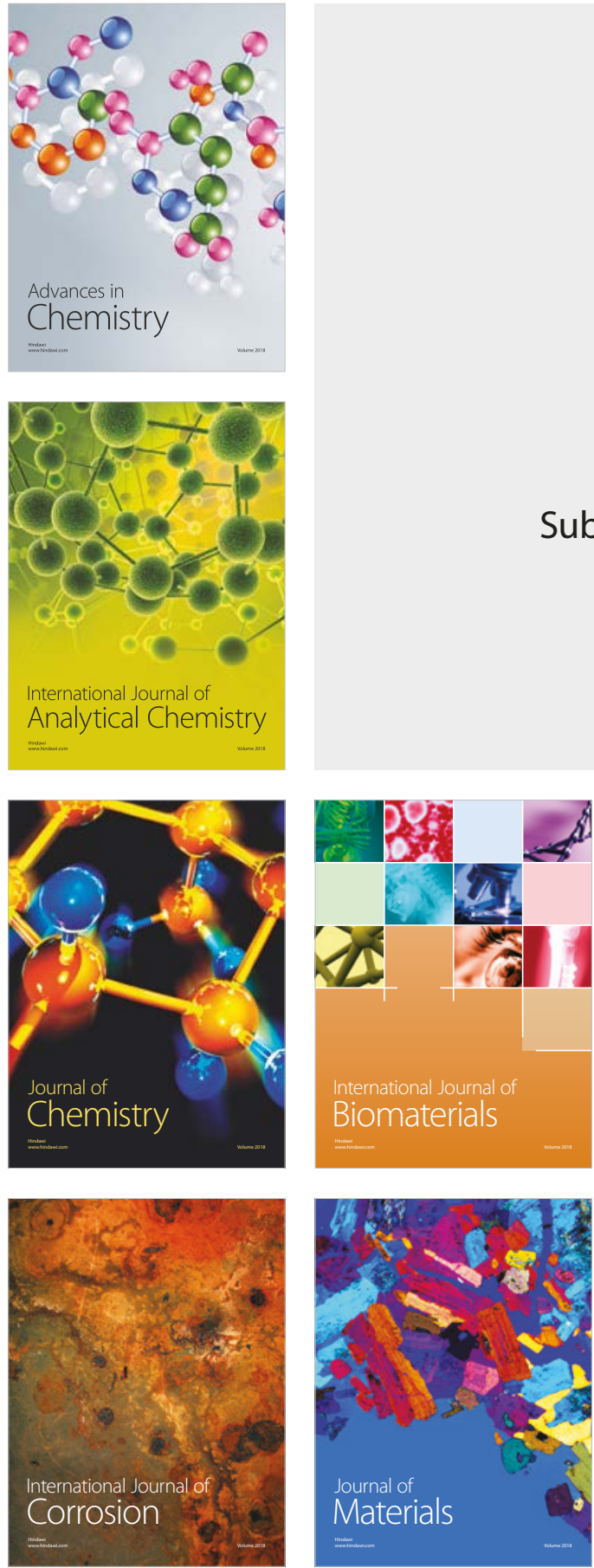

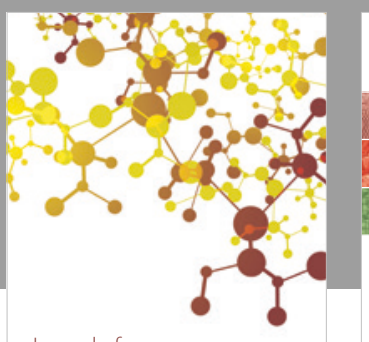

Journal of

Applied Chemistry


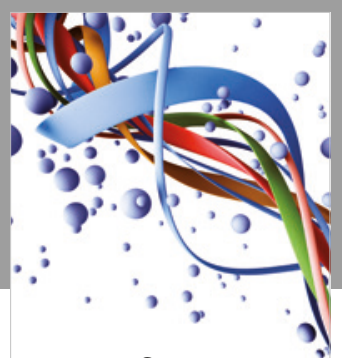

Scientifica



Polymer Science

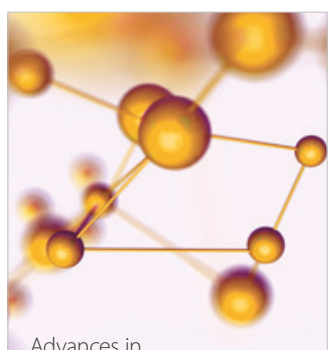

Physical Chemistry
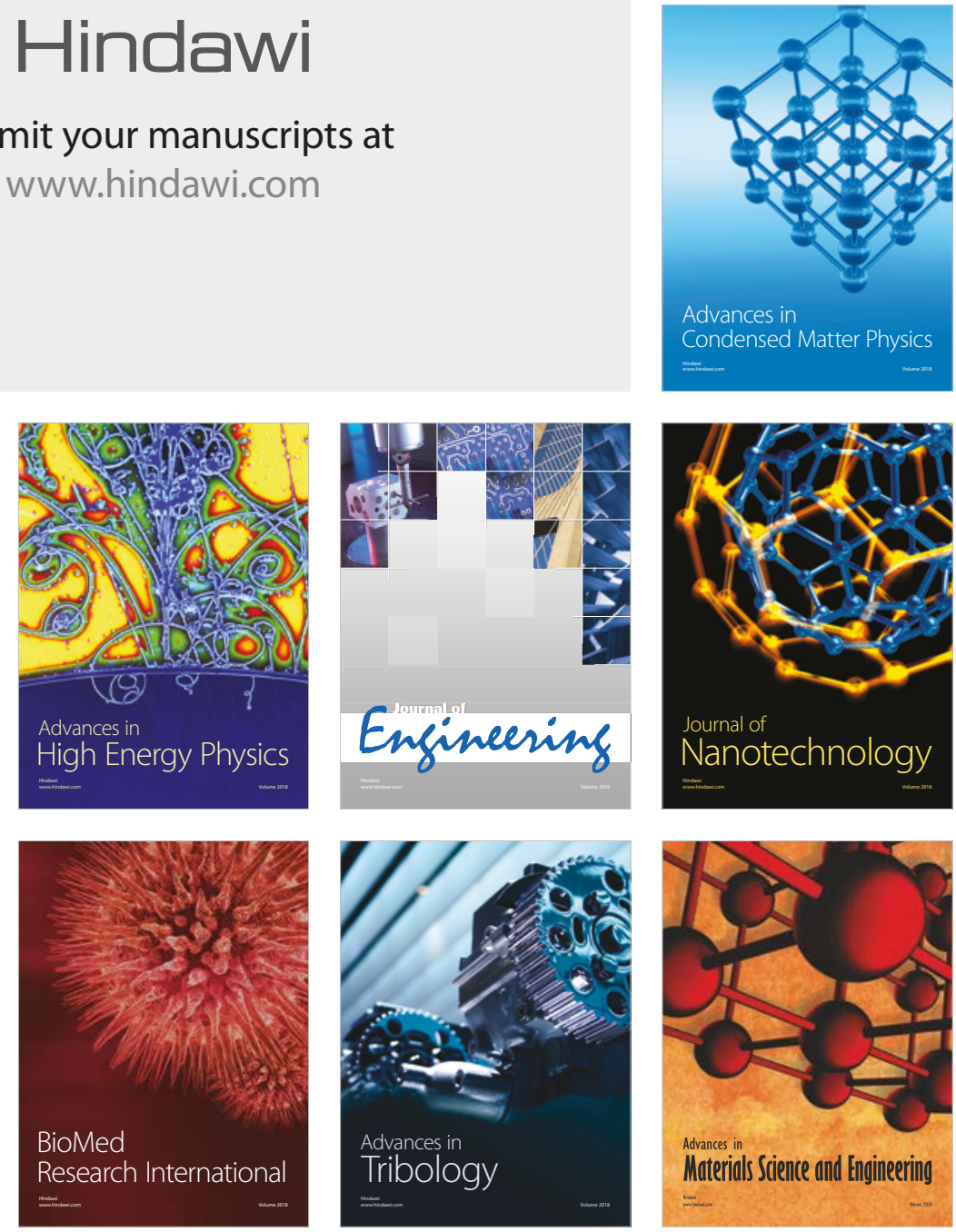